\title{
Understanding the catalase-like activity of a bio-inspired manganese(II) complex with a pentadentate NSNSN ligand framework. A computational insight into the mechanism.
}

Maria Letizia Merlini, ${ }^{a}$ George J. P. Britovsek, ${ }^{\mathrm{b}}$ Marcel Swart, ${ }^{\mathrm{c}, \mathrm{d}}$ Paola Belanzoni*e,f

a) Laboratoire de Chimie et Biochimie Computationnelles, Institut des Sciences et Ingénierie Chimiques, École Polytechnique Fédérale de Lausanne (EPFL), Av. F.-A. Forel 2, CH-1015 Lausanne, Switzerland

b) Department of Chemistry, Imperial College London, Exhibition Road, London, United Kingdom

c) Institut de Química Computacional i Catàlisi (IQCC) and Departament de Química, Universitat de Girona, Campus Montilivi, Facultat de Ciències, 17071 Girona, Spain

d) Institució Catalana de Recerca i Estudis Avançats (ICREA), Pg. Lluis Companys 23, 08010 Barcelona, Spain

e) Dipartimento di Chimica, Biologia e Biotecnologie, Università degli Studi di Perugia, Via Elce di Sotto 8, I-06123, Perugia, Italy

f) Istituto di Scienze e Tecnologie Molecolari del CNR (CNR-ISTM), clo Dipartimento di Chimica, Biologia e Biotecnologie, Università degli Studi di Perugia, via Elce di Sotto 8, I-06123, Perugia, Italy

\begin{abstract}
The mechanism of $\mathrm{H}_{2} \mathrm{O}_{2}$ dismutation catalyzed by the recently reported 2,6-bis[((2pyridylmethyl)thio)methyl]pyridine-Mn(II) complex ([MnS$\left.\left.{ }_{2} \mathrm{Py}_{3}(\mathrm{OTf})_{2}\right]\right)$ has been investigated by density functional theory using the $\mathrm{S} 12 \mathrm{~g}$ functional. The complex has been analyzed in terms of its coordination properties and the reaction of $\left[\mathrm{MnS}_{2} \mathrm{Py}_{3}\right]^{2+}$ in a distorted square pyramidal coordination geometry with two hydrogen peroxide molecules has been investigated in our calculations. The sextet, quartet and doublet potential energy profiles of the catalytic reaction have been explored. In the first dismutation process the rate-determining step (RDS) is found to be the asymmetric $\mathrm{O}-\mathrm{O}$ bond cleavage, which occurs on the sextet potential energy profile. A subsequent spin crossover from sextet to quartet can take place generating a stable $\mathrm{Mn}(\mathrm{IV})$ dihydroxo intermediate. This could disfavor the ping-pong mechanism commonly considered to describe the
\end{abstract}


$\mathrm{H}_{2} \mathrm{O}_{2}$ dismutation reaction, where the binding of the first $\mathrm{H}_{2} \mathrm{O}_{2}$ substrate leads to the release of one $\mathrm{H}_{2} \mathrm{O}$ product and the conversion of the catalyst into a Mn(IV) oxo complex. The formation of this stable intermediate, featuring a peculiar trigonal prismatic coordination geometry paves the way for an alternative reaction pathway for the second dismutation process, termed the dihydroxo mechanism, where two water molecules and dioxygen are easily and simultaneously formed. The competing channels have different spin states: the sextet reaction pathway corresponds to the pingpong mechanism, whereas the quartet reaction follows preferably the dihydroxo mechanism. The doublet reaction path is energetically disfavored for both channels. For the ping-pong mechanism, the RDS in the second dismutation process is represented by the second hydrogen-abstraction from $\mathrm{H}_{2} \mathrm{O}_{2}$, with a calculated energy barrier very close to that of the RDS in the first dismutation reaction. Explicit solvent molecules, counterions and trace amounts of water are found to further support the preference for the asymmetric O-O bond breaking, by favoring the end-on coordination mode of $\mathrm{H}_{2} \mathrm{O}_{2}$ to the catalyst.

Keywords: bio-inspired manganese catalyst, $\mathrm{H}_{2} \mathrm{O}_{2}$ dismutation reaction, multispin-state mechanism, spin-crossover reactivity, DFT calculations

\section{Introduction}

Oxygen, though essential for aerobic metabolism, can be converted into toxic metabolites, such as the superoxide anion $\left(\mathrm{O}_{2}^{-}\right)$, hydroxyl radical $\left(\mathrm{OH}^{*}\right)$, and hydrogen peroxide $\left(\mathrm{H}_{2} \mathrm{O}_{2}\right)$, collectively known as reactive oxygen species (ROS). ROS production is associated with numerous pathological conditions including ischemic and inflammatory processes. ${ }^{1)}$ These powerful oxidants can attack proteins, lipids, lipoproteins, nucleic acids and carbohydrates, ${ }^{2)}$ thereby turning into lethal agents against cell structure and functioning. In vivo protection occurs via mechanisms to control the level of ROS, including the use of two key classes of metalloenzymes, the superoxide dismutases (SOD) 
and catalases (CAT), which catalyze the dismutation processes of superoxide and hydrogen peroxide, respectively. Although the majority of CATs rely on the heme group for catalysis, an alternative class of manganese-dependent CATs (MnCATs) has been identified in three different bacteria. ${ }^{3)}$ Crystallographic studies have revealed that these MnCATs contain a dinuclear Mn core with bridging carboxylate and oxide ligands. ${ }^{4)}$ Several studies have been dedicated to develop novel synthetic MnCATs biomimetic complexes. ${ }^{5}$ The first example of a dinuclear Mn(II) catalyst mimicking the natural enzyme function has been reported by Dismukes and coworkers. ${ }^{6}$ More recently, catalase biomimetics include single-site Mn complexes, often showing both SOD and CAT activity, which can be used as artificial small molecule catalysts for ROS detoxification and are promising as therapeutics. ${ }^{7}$ Indeed, some Mn(III)-porphyrin (for example AEOL10150), Mn(III)salen (for example EUK-113) and seven-coordinated Mn(II)-macrocyclic polyamine complexes (for example M40403) have entered clinical tests. ${ }^{8-12}$ Although Mn-polyamine complexes show very high SOD-mimetic activity, ${ }^{13}$ certain Mn-porphyrin and Mn-salen complexes exhibit dual SOD and CAT activity. ${ }^{14-17}$ Additional functions of manganese complexes are known such as oxidation, ${ }^{18-20}$ reduction, ${ }^{21}$ or sulfur-oxygenation. ${ }^{22}$

In a recent paper by Britovsek, Bonchio and coworkers, ${ }^{23}$ the synthesis and characterization of a bio-inspired $\mathrm{Mn}(\mathrm{II})$ complex with a linear pentadentate ligand framework containing soft sulfur donors and an alternating NSNSN binding motif is described. This seven-coordinate Mn(II) complex, with two triflate counterions, $\left[\mathrm{MnS}_{2} \mathrm{Py}_{3}(\mathrm{OTf})_{2}\right] \quad\left(\mathrm{S}_{2} \mathrm{Py}_{3}=2,6-b i s[((2-\right.$ pyridylmethyl)thio)methyl]pyridine), displays excellent dual CAT/SOD-like antioxidant activity both in acetonitrile and in aqueous solution, with high turnover efficiency, surpassing the $\mathrm{Mn}$ (II) analogues with hard nitrogen and oxygen donor ligands $\left[\mathrm{Mn}(\mathrm{NMe})_{2} \mathrm{Py}_{3}(\mathrm{OTf})_{2}\right]\left((\mathrm{NMe})_{2} \mathrm{Py}_{3}=\mathrm{N}-\right.$ methyl-(aminomethyl)pyridine), $\quad\left[\mathrm{Mn}(\mathrm{NTs})_{2} \mathrm{Py}_{3}(\mathrm{OTf})_{2}\right] \quad\left((\mathrm{NTs})_{2} \mathrm{Py}_{3}=\quad \mathrm{N}, \mathrm{N}^{\prime}\right.$-ditosyl-2,6-bis[(2pyridylmethyl)amino)methyl $]$ pyridine $), \quad$ and $\quad\left[\mathrm{MnO}_{2} \mathrm{Py}_{3}(\mathrm{OTf})_{2}\right] \quad\left(\mathrm{O}_{2} \mathrm{Py}_{3} \quad=\quad 2,6-\right.$ bis$[((2-$ pyridylmethyl)oxy)methyl]pyridine). ${ }^{23}$ The CAT-like activity of the $\left[\mathrm{MnS}_{2} \mathrm{Py}_{3}(\mathrm{OTf})_{2}\right]$ complex, which is stable in an aqueous environment, is also higher than that of salen-type complexes, which 
decompose irreversibly in water after several minutes. The $\mathrm{pH}$ of the solution appears to have a major influence on the stability of the catalyst. A very active and remarkably stable catalyst performance is generated by the addition of base $(\mathrm{NaOH}, 1 \mathrm{M}, 10 \mu \mathrm{L})$ as well as by addition of imidazole in aqueous solution using a borate buffer ( $\mathrm{pH} 9$ ). The different reactivity of $\left[\mathrm{MnS}_{2} \mathrm{Py}_{3}(\mathrm{OTf})_{2}\right]$ containing sulfur donors compared to related ligands with $\mathrm{N}$ or $\mathrm{O}$ donors is unclear at this stage. However, a special role of sulfur ligation in biological systems based on manganese and related metal complexes, in particular cytochrome P450, is well documented. ${ }^{18-}$ 22,24,25 The ability of sulfur donors to stabilize high valent metal complexes, while being susceptible to oxidation themselves, is not fully understood but must require careful balancing of the electronic and steric requirements. Noteworthy in this context, the sulfur donors in a manganese complex with a pentadentate thio-ketone-containing SNNNS ligand were found to inhibit antioxidant activity. ${ }^{26}$ An understanding of the mechanism of the catalase reaction is a fundamental task for ligand rational design and tuning of single-site manganese-based catalytic complexes in order to achieve improved catalase activity. Currently, only few examples of theoretical investigations of the hydrogen peroxide dismutation reaction $\left(2 \mathrm{H}_{2} \mathrm{O}_{2} \rightarrow 2 \mathrm{H}_{2} \mathrm{O}+\mathrm{O}_{2}\right)$ mechanism are available in the literature and, to our knowledge, only using Mn(III)-salen complexes as catalysts. Abashkin and coworkers ${ }^{27-29}$ presented the first theoretical investigations on $\mathrm{Mn}(\mathrm{III})$-salen complexes (in particular, the EUK-8 complex) using density functional theory (DFT) in three different spin states singlet, triplet and quintet. The authors proposed the general ping-pong mechanism in which the first hydrogen peroxide molecule binds to the $\mathrm{Mn}(\mathrm{III})$ center, oxidizes the metal, and releases a water molecule while forming the oxomanganese intermediate $\mathrm{Mn}(\mathrm{V})=\mathrm{O}$. A second hydrogen peroxide molecule reacts with the oxomanganese species and the oxygen atom is transferred to hydrogen peroxide forming dioxygen and water. The experimental study reported by Nocera and coworkers ${ }^{30}$ concurred with the DFT prediction by Abashkin.

Theoretical studies on the mechanism of functional biomimetics of enzymes, although fundamentally important for a better understanding of the enzyme and the design of MnCATs with 
improved therapeutic properties, is a challenging task: different spin states are usually involved but many standard DFT functionals fail to predict the correct energy relationship between them. ${ }^{31,32}$ For our investigations we used the $\mathrm{S} 12 \mathrm{~g}$ functional which has been recently recognized as a reliable tool for providing a correct picture of the spin state energy order in complicated transition metal systems and its accurate performance is well documented. ${ }^{33-35}$

We are not aware of any studies in the literature on the mechanism of catalase-type reactions catalyzed by the pentadentate NSNSN-Mn(II) complex. This is precisely the aim of this work. We present here our S12g DFT investigation on the mechanism of $\mathrm{H}_{2} \mathrm{O}_{2}$ dismutation reaction catalyzed by the $\left[\mathrm{Mn}(\mathrm{II}) \mathrm{S}_{2} \mathrm{Py}_{3}(\mathrm{OTf})_{2}\right]$ complex on the three different potential energy surfaces of the doublet, quartet and sextet spin states.

\section{Methods and Computational Details}

A comprehensive DFT computational study was performed using the ADF2014.05 $5^{36-38}$ and the related Quantum-regions Interconnected by Local Descriptions (QUILD) program ${ }^{39)}$ to identify the structures of the reactant complexes, intermediates, transition states and product complexes of the hydrogen peroxide dismutation reaction catalyzed by $\left[\mathrm{MnS}_{2} \mathrm{Py}_{3}\right]^{2+}$. For geometry optimizations, calculations were carried out using the GGA functional BP86, ${ }^{40,41}$ including Grimme's $\mathrm{D}_{3}$ dispersion correction $\left(\mathrm{BP} 86-\mathrm{D}_{3}\right){ }^{42}$ All atoms were described with a Slater-type DZP double- $\zeta$ quality basis set (TZP triple- $\zeta$ for Mn), using the frozen core approximation (core small). Solvation effects have been taken into account by the Conductor like Screening Model COSMO $^{43-45}$ using acetonitrile as solvent and the default COSMO surface in ADF2014.05 version (Esurf). Relativistic effects were treated with the scalar zero-order regular approximation, ZORA model. ${ }^{46,47}$ Final energies have been calculated by single point $\mathrm{S} 12 \mathrm{~g}$ functional ${ }^{33)}$ calculations on the optimized BP86- $\mathrm{D}_{3} / \mathrm{DZP}$ solution phase structures with a TZ2P triple- $\zeta$ quality basis set with two polarization functions (core small) for all atoms. As mentioned above, the $\mathrm{S} 12 \mathrm{~g}$ functional has been shown to be 
a reliable tool for the energetics of spin states and to improve significantly the prediction of the reaction barriers in transition metal systems. ${ }^{34,48}$ This spin-state consistent S12g density functional was designed to work well for spin states based on the observation ${ }^{49}$ that the difference between the good (OPBE) and bad (PBE) performance for spin states ${ }^{50}$ can be traced back to the region of $\mathbf{s}<1$ in the exchange enhancement factor. This was used to design the SSB-D ${ }^{51}$ and $\mathrm{S} 12 \mathrm{~g}^{33}$ functionals, including Grimme dispersion. ${ }^{52,53}$ Frequency calculations at the same S12g/TZ2P level of theory have been also performed to identify all stationary points as minima (zero imaginary frequencies) or transition states (one imaginary frequency) and to compute the Gibbs free energies. For all calculations carried out with $\mathrm{BP} 86-\mathrm{D}_{3}$ the Becke grid of Normal quality was employed, whereas S12g calculations were performed with a Becke grid of VeryGood quality. ${ }^{54}$ All DFT calculations were carried out using the unrestricted Kohn-Sham scheme for the open shell sextet, quartet and doublet spin states.

\section{Results and Discussion}

\section{The initial complex}

To avoid uncertainties connected with using an incomplete model, ${ }^{29}$ the entire complex reacting with hydrogen peroxide will be considered in our DFT calculations. To this aim, since no X-ray crystal structure of $\left[\mathrm{MnS}_{2} \mathrm{Py}_{3}(\mathrm{OTf})_{2}\right]$ is available yet, preliminary geometry optimizations to analyze the coordination behavior of seven- and five-coordinate $\mathrm{Mn}(\mathrm{II})$ complexes have been performed for the experimentally measured sextet spin state. The ${ }^{19} \mathrm{~F}$ NMR spectrum for $\left[\mathrm{MnS}_{2} \mathrm{Py}_{3}(\mathrm{OTf})_{2}\right]$ in $\mathrm{CD}_{3} \mathrm{CN}$ at room temperature (see Fig. S4 ESI in ref ${ }^{23}$ ) supports a sixcoordinate geometry, with the NSNSN ligand in a $\operatorname{fmf}$ coordination mode (for octahedral complexes the ligand coordination mode is conveniently described using the meridional $(m)$ and facial $(f)$ notation for each consecutive set of three donors within the ligand, $f m f=$ fac-mer-fac), with one 
triflate ligand occupying the axial position and the other in the second coordination sphere. Triflate ligands are generally weakly coordinating and are easily displaced in acetonitrile or aqueous solution. For example, a dynamic equilibrium between two iron(II) complexes with the related pentadentate ligand 2,6-bis[(methyl(2-pyridylmethyl)amino)-N-methyl]pyridine and two triflate anions, one with a seven-coordinate pentagonal bipyramidal geometry and the other with a fivecoordinate trigonal bipyramidal geometry upon loss of the two triflate ligands, has been previously reported. ${ }^{55}$ Moreover, based on the XRD structure of the oxygen-containing analogue $\left[\mathrm{MnO}_{2} \mathrm{Py}_{3}(\mathrm{OTf})_{2}\right]{ }^{23}$ which shows a distorted pentagonal bipyramidal coordination geometry with two triflate ligands in the axial positions, a possible 7-5 coordination equilibrium could have an important impact on the study of $\left[\mathrm{MnS}_{2} \mathrm{Py}_{3}(\mathrm{OTf})_{2}\right]$ in solution, where spin and coordination equilibria are essential features of its catalytic action. To ascertain the geometrical structure, a detailed study of the $\left[\mathrm{MnS}_{2} \mathrm{Py}_{3}(\mathrm{OTf})_{2}\right]$ complex in the sextet $(\mathrm{S}=5 / 2)$ spin state, through COSMO solvent calculations, also including two explicit solvent molecules in the second coordination sphere, is reported in the SI (Figures S1-S4). The most stable species is shown in Figure 1 (left), where the ligand has a fmf coordination mode, with one triflate ligand in the axial position, in agreement with the octahedral geometry supported by NMR spectroscopy. 

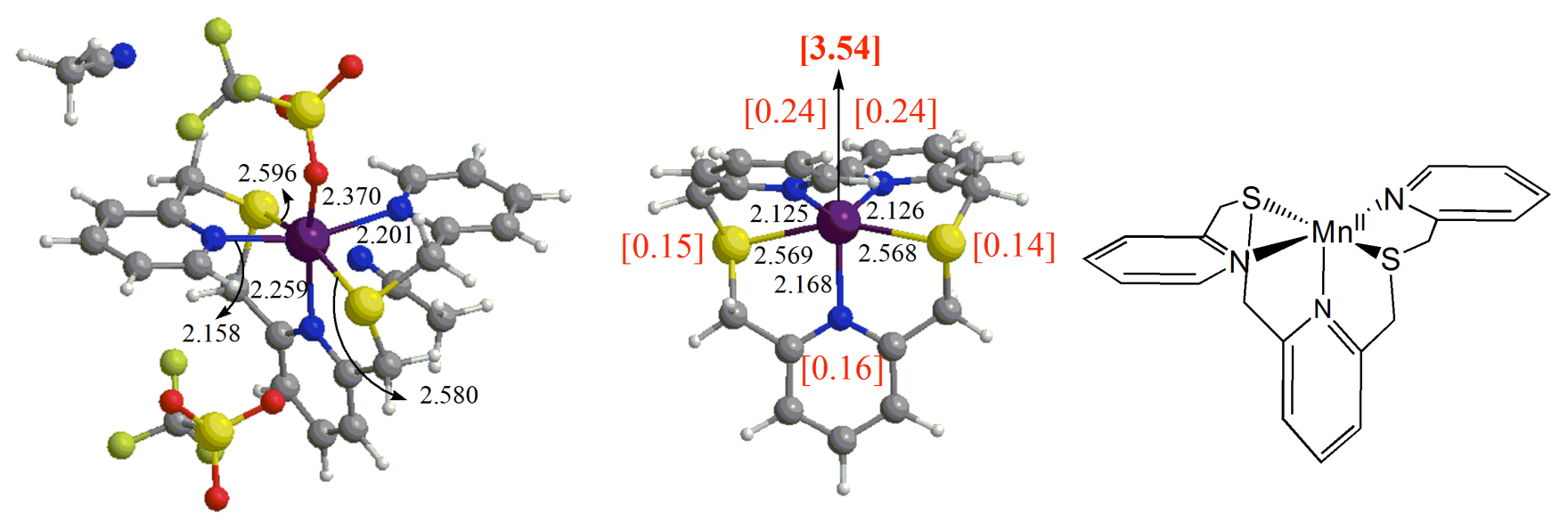

Figure 1. Left) Optimized geometry of the most stable coordination geometry (denoted SBPY-6 [OTf] in Figure $\mathrm{S} 1$ in the $\mathrm{SI}$ ) of the $\left[\mathrm{MnS}_{2} \mathrm{Py}_{3}(\mathrm{OTf})_{2}\right]$ complex (two explicit acetonitrile solvent molecules are also included $)$ in the sextet $(S=5 / 2)$ spin state. Middle) Optimized geometry of the most stable $\left[\mathrm{MnS}_{2} \mathrm{Py}_{3}\right]^{2+}$ complex in the sextet spin state. Right) Schematic picture of the initial catalyst $\left[\mathrm{MnS}_{2} \mathrm{Py}_{3}\right]^{2+}$ complex under investigation. Distances are in $\AA$. Values in square bracket refer to the calculated spin densities (based on Multiple Derived Charges (MDC-q) analysis ${ }^{56}$ ) on Mn and $\mathrm{N}, \mathrm{S}$ donor atoms.

A similar COSMO solvent analysis has been carried out on the bare $\left[\mathrm{MnS}_{2} \mathrm{Py}_{3}\right]^{2+}$ complex, in the absence of triflate ions and explicit solvent molecules, showing that the sextet spin state $(\mathrm{S}=5 / 2)$ is the ground state, with the quartet $(S=3 / 2)$ and the doublet $(S=1 / 2)$ spin states lying at higher energies in the order. We have found that the most stable geometry for the $\left[\mathrm{MnS}_{2} \mathrm{Py}_{3}\right]^{2+}$ complex can be described as distorted square pyramidal with the two nitrogen donors of the terminal Py rings and the two sulfur atoms in the equatorial plane and the nitrogen atom of the central Py ring representing the apical position of the pyramid (see Figure 1 middle). This geometry is also seen in related Group 12 metal complexes of zinc and mercury with this ligand. ${ }^{57}$ Due to the absence of any crystal field stabilization energy for $\mathrm{d}^{10}$ and $\mathrm{HS} \mathrm{d}^{5}$ metal complexes, the coordination 
geometries are largely dictated by steric effects.

For our mechanistic study we therefore considered $\left[\mathrm{MnS}_{2} \mathrm{Py}_{3}\right]^{2+}$ with an open coordination site at the axial position of a pseudo octahedral geometry (see Figure 1 right) in a sextet spin ground state as the initial catalyst precursor complex, which is in agreement with both the experimental ${ }^{19} \mathrm{~F}$ NMR spectrum and the experimental magnetic moment value of 5.9-6.0 $\mu_{\mathrm{B}}$ (Fig. S4 and S1 ESI in ref. ${ }^{23}$ ). A description of the spin density distribution in the $\left[\mathrm{MnS}_{2} \mathrm{Py}_{3}\right]^{2+}$ initial complex (IC) is given in Figure 1 (middle). In the sextet spin state the spin density on $\mathrm{Mn}$ is 3.54 , less than the expected $5 \alpha$-spin unpaired electrons for a high-spin $\mathrm{d}^{5} \mathrm{Mn}(\mathrm{II})$ metal atom. Interestingly, additional spin density delocalizes over the $\mathrm{N}(0.24,0.16$ and 0.24$)$ and $\mathrm{S}$ donor atoms $(0.14$ and 0.15$)$ of the ligand (total 0.93), which leads to an overall electronic structure in the sextet state (roughly $4 \alpha$-spin unpaired electrons on $\mathrm{Mn}$ and $1 \alpha$-spin unpaired electron on the ligand). According to our description, the manganese ion in the initial complex $\left[\mathrm{MnS}_{2} \mathrm{Py}_{3}\right]^{2+}$ should bear a physical oxidation state III. This finding suggests that the ligand can display non-innocent character. Redox noninnocence of S-containing ligands is not unprecedented and has been extensively illustrated by Wieghardt and Sproules ${ }^{58}$ in their seminal work on transition metal bis(dithiolene) complexes by probing the sulfur composition of the frontier orbitals. The five singly occupied molecular orbitals for the initial $\left[\mathrm{MnS}_{2} \mathrm{Py}_{3}\right]^{2+}$ complex are presented in Figure 2, with their percentage compositions (main contributions in terms of individual N, S and Mn atoms) and energies. 

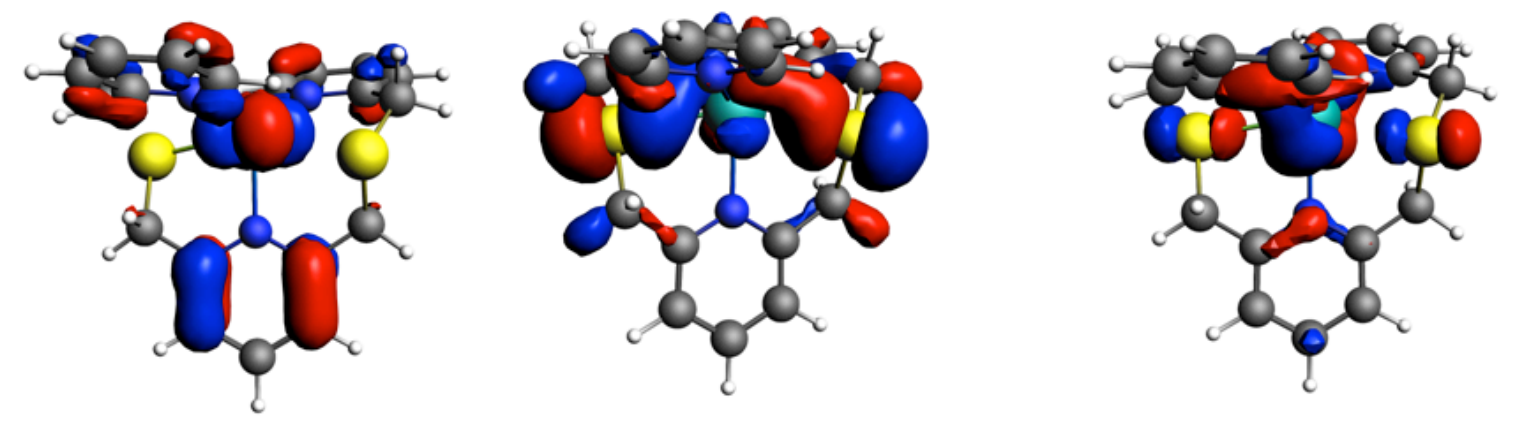
$63 a=36 \% d x z+19 \% d z^{2}$ $\mathrm{E}=-7.60 \mathrm{eV}$
$67 \mathrm{a}=24 \% d y z+20 \% 3 p_{z} S+20 \% 3 p_{z} S$ $\mathrm{E}=-7.15 \mathrm{eV}$

$68 \mathrm{a}=56 \% d x y+6 \% 2 \mathrm{p}_{x} \mathrm{~N}+6 \% 2 \mathrm{p}_{x} \mathrm{~N}$ $E=-6.58 \mathrm{eV}$
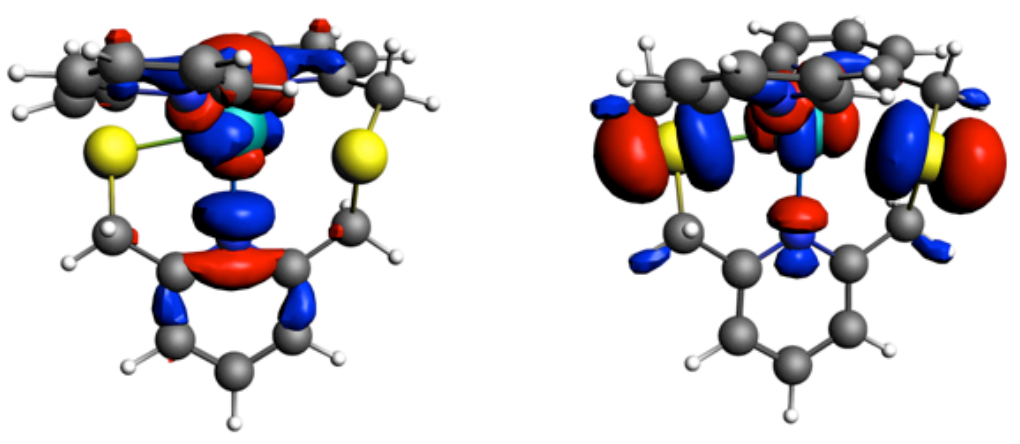

$69 \mathrm{a}=57 \% d \mathrm{x}^{2}-\mathrm{y}^{2}+11 \% 2 \mathrm{p}_{\mathrm{y}} \mathrm{N}$ $E=-6.26 \mathrm{eV}$ $70 a=26 \% d z^{2}+17 \% d x z+12 \% 3 p_{z} S+12 \% 3 p_{z} S$
$E=-5.40 e V$

Figure 2. Singly occupied MOs ( $\alpha$ spin), percentage compositions (main contributions of individual $\mathrm{Mn}, \mathrm{N}$ and $\mathrm{S}$ atoms) and energies for the initial complex $\left[\mathrm{MnS}_{2} \mathrm{Py}_{3}\right]^{2+}$. The $\mathrm{y}$ axis is oriented along the Mn-N axial ligand, the $\mathrm{z}$ axis along the equatorial S-Mn-S and the $\mathrm{x}$ axis along the equatorial $\mathrm{N}$ Mn-N direction.

The lower lying MO (63 a) in this set is mainly a Mn dxz/dz hybrid orbital with no involvement of $\mathrm{N}$ and $\mathrm{S}$ donor atoms. A substantial S $3 \mathrm{p}_{\mathrm{z}}$ character is observed in the $67 \mathrm{a}(\mathrm{dyz})$ and $70 \mathrm{a}(\mathrm{dz} / \mathrm{dxz})$ MOs, whereas 68 a (dxy) MO has contributions from equatorial N 2p orbitals and $69 a\left(\mathrm{dx}^{2}-\mathrm{y}^{2}\right)$ MO from axial $\mathrm{N} 2 \mathrm{p}_{\mathrm{y}}$ orbital, providing evidence of the non innocent nature of the NSNSN ligand which, interacting with the five $\mathrm{d}$ metal orbitals, acquires a total of 1 unpaired electron delocalized over the N/S donor atoms. 


\section{First dismutation reaction}

In this subsection, we investigate the first dismutation reaction of one hydrogen peroxide molecule catalyzed by the $\left[\mathrm{MnS}_{2} \mathrm{Py}_{3}\right]^{2+}$ complex, which can take place for three different spin states of $\mathrm{Mn}(\mathrm{II})$ (sextet, quartet and doublet). According to the ping-pong mechanism commonly reported in the literature, ${ }^{27-29}$ the first dismutation reaction leads to the simultaneous formation of a water molecule and an oxo manganese intermediate. The coordination of hydrogen peroxide to the Mn(II) metal (denoted $\mathrm{RC}_{\mathrm{I}}$ in Scheme 1), which induces the O-O bond cleavage, could in principle provide a high-valent manganese (IV) oxo compound $\left(\mathrm{PC}_{\mathrm{Ioxo}}\right)$ through the formation of a monohydroxo (plus free hydroxide) $\left(\mathrm{I}_{\mathrm{OH}}\right)$ or via a stable dihydroxo intermediate $\left(\mathrm{I}_{\mathrm{OHOH}}\right)$ (see Scheme 1). As recognized by several reports, ${ }^{59-65}$ manganese(IV) dihydroxo intermediates are potentially capable of hydrogen abstraction and therefore could represent key active intermediates and alternatives to manganese(IV) oxo compounds for the subsequent second dismutation reaction.
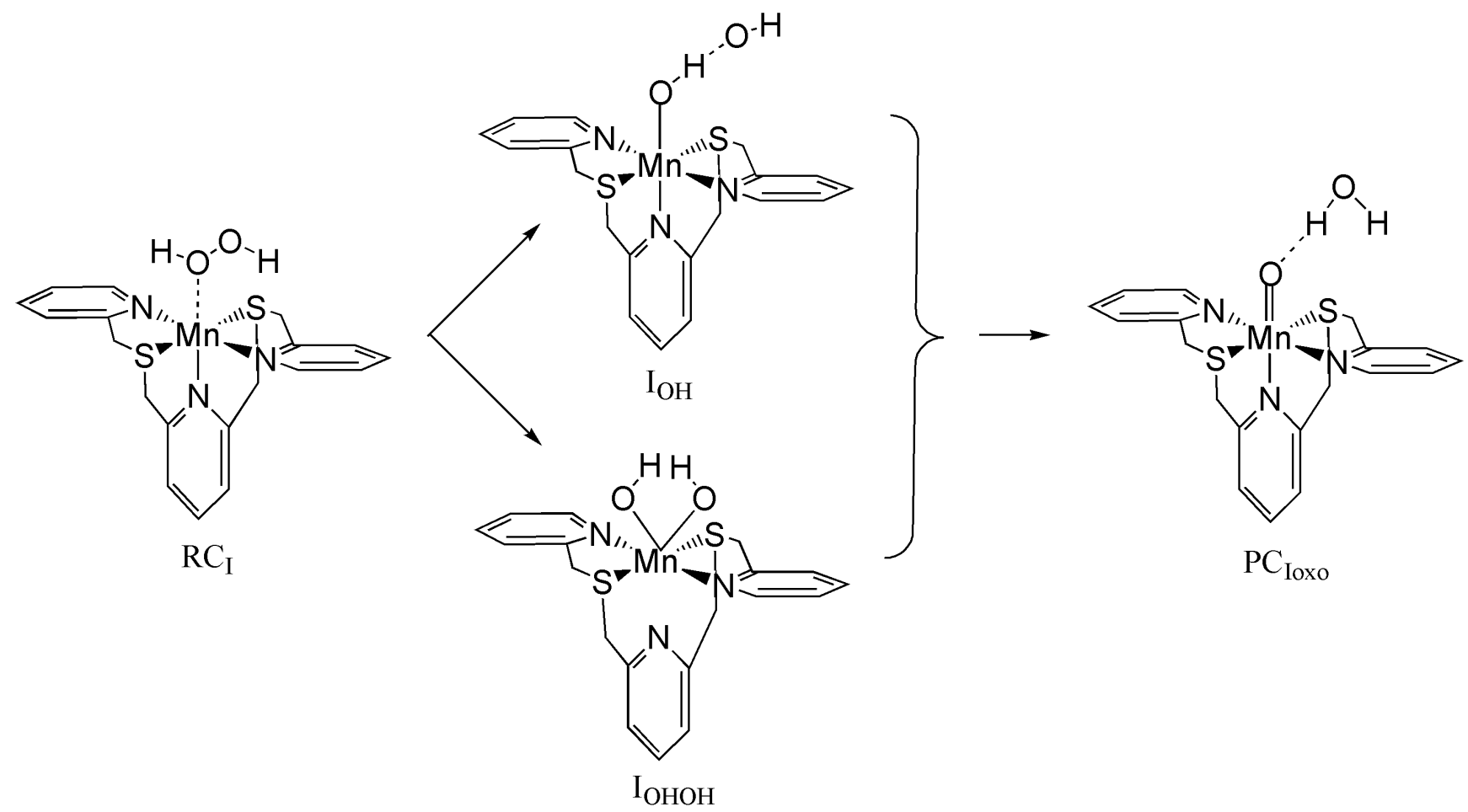
Scheme 1. Proposed intermediates and products of the first dismutation reaction of hydrogen peroxide catalyzed by $\left[\mathrm{MnS}_{2} \mathrm{Py}_{3}\right]^{2+}: \mathrm{RC}_{\mathrm{I}}$ represents the reactant complex, $\mathrm{I}_{\mathrm{OH}}$ the $\mathrm{Mn}$ monohydroxo intermediate, $\mathrm{I}_{\mathrm{OHOH}}$ the $\mathrm{Mn}(\mathrm{IV})$ dihydroxo intermediate and $\mathrm{PC}_{\mathrm{Ioxo}}$ the $\mathrm{Mn}(\mathrm{IV})$ oxo intermediate plus a product water molecule.

The question we address here is whether the first dimutation reaction with $\left[\mathrm{MnS}_{2} \mathrm{Py}_{3}\right]^{2+}$ can be described with the classical ping-pong mechanism leading to the formation of an oxo manganese(IV) intermediate and a water molecule $\left(\mathrm{PC}_{\mathrm{Ioxo}}\right)$ or with a different mechanism, involving the formation of a stable dihydroxo $\mathrm{Mn}(\mathrm{IV})$ intermediate $\left(\mathrm{I}_{\mathrm{OHOH}}\right)$.

\section{The reactant complex}

The optimized geometries of the reactant complexes, denoted $\mathrm{RCx}(\mathrm{x}=\mathrm{s}$ for sextet, $\mathrm{x}=\mathrm{q}$ for quartet and $\mathrm{x}=\mathrm{d}$ for doublet), in the three different spin states are shown in Figure 3.

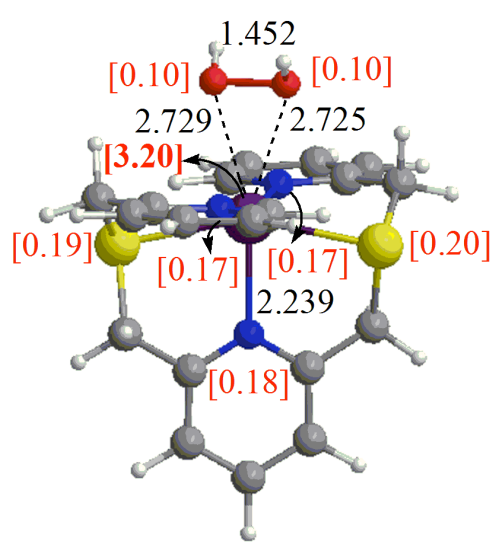

$\mathrm{RCs}^{\text {side-on }} 5.4 \mathrm{kcal} / \mathrm{mol}$

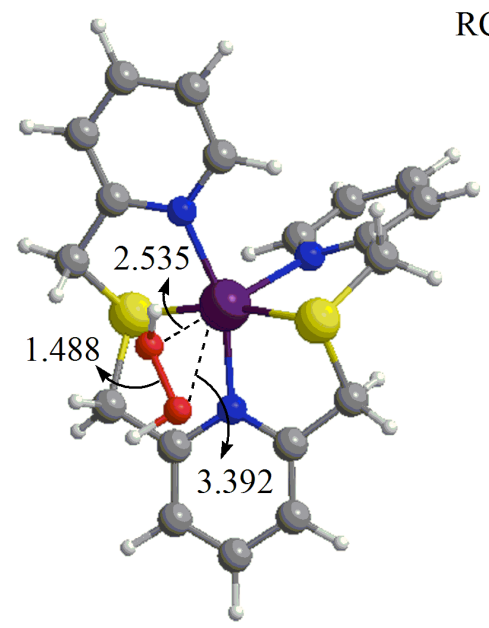

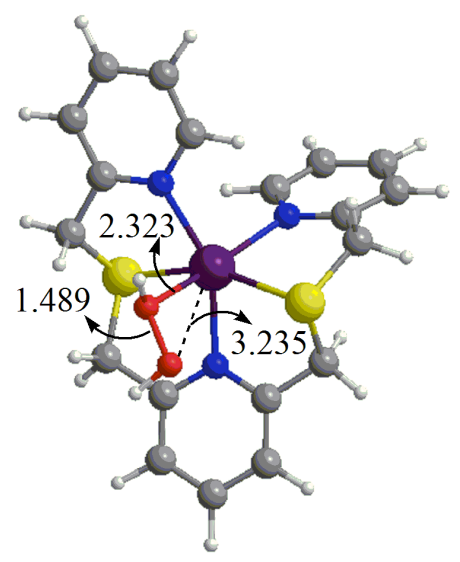

$\mathrm{RCs}^{\text {end-on }} 9.7 \mathrm{kcal} / \mathrm{mol}$

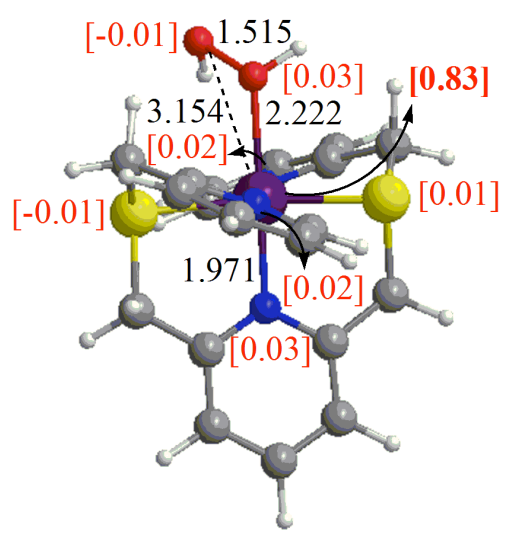


Figure 3. Optimized geometries of the reactant complexes $\left[\mathrm{MnS}_{2} \mathrm{Py}_{3}\left(\mathrm{H}_{2} \mathrm{O}_{2}\right)\right]^{2+}$ in the sextet

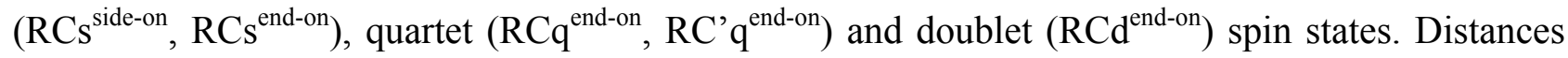
are in $\AA$ and Gibbs free energies are given in $\mathrm{kcal} / \mathrm{mol}$ with respect to the sum of the Gibbs free energies of the separate reactants $\left(\left[\mathrm{MnS}_{2} \mathrm{Py}_{3}\right]^{2+}+\mathrm{H}_{2} \mathrm{O}_{2}\right)$ in their spin ground states taken as zero reference energy. Values in square brackets are spin densities (based on Multiple Derived Charges (MDC-q) analysis) calculated on $\mathrm{Mn}, \mathrm{N}$ and $\mathrm{S}$ atoms.

For the sextet spin state the reactant complex has been calculated for two different coordination modes: one showing an end-on binding of the hydrogen peroxide molecule to the metal center (denoted RCs ${ }^{\text {end-on }}, \mathrm{Mn}-\mathrm{O} 1=2.323 \AA, \mathrm{Mn}-\mathrm{O} 2=3.235 \AA$ ), the other a side-on approach of the substrate (denoted RCs ${ }^{\text {side-on }} \mathrm{Mn}-\mathrm{O} 1=2.725 \AA$, Mn-O2=2.729 $\AA$ ). Additionally, the coordination mode of the pentadentate ligand changes from $m m f$ in $\mathrm{RCs}^{\text {end-on }}$ to $f m f$ in $\mathrm{RCs}^{\text {side-on }}$. The latter is more stable by $4.3 \mathrm{kcal} / \mathrm{mol}$, but both $\mathrm{RCs}^{\text {side-on }}$ and $\mathrm{RCs}^{\text {end-on }}$ are less stable than the sum of the Gibbs free energies of the separate reactants $\left(\left[\mathrm{MnS}_{2} \mathrm{Py}_{3}\right]^{2+}+\mathrm{H}_{2} \mathrm{O}_{2}\right)$ by 5.4 and $9.7 \mathrm{kcal} / \mathrm{mol}$, respectively. The binding of hydrogen peroxide is endothermic in the sextet spin state. The participation of similar species in catalytic processes has been invoked, for instance, for Mnporphyrin complexes, and it was also suggested that the $\mathrm{O}-\mathrm{O}$ bond of $\mathrm{H}_{2} \mathrm{O}_{2}$ coordinated in the sideon mode may dissociate, resulting in two $\mathrm{OH}$ groups bound to the metal center. ${ }^{66}$ However, it should be noticed that, apart from the different approaches of $\mathrm{H}_{2} \mathrm{O}_{2}$ to $\mathrm{Mn}$, coordination of $\mathrm{H}_{2} \mathrm{O}_{2}$ occurs in a cis position with respect to the central Py ring of the ligand in the RCs ${ }^{\text {end-on }}$ structure, whereas in $\mathrm{RCs}^{\text {side-on }}$ it takes place trans to it, thus retaining the initial catalyst coordination mode (see Figure 1 left). This finding suggests that the NSNSN ligand is flexible enough to cope with substrate coordination. The different coordination mode (ligand plus substrate) around the central 
metal can also account for the less stable $\mathrm{RCs}^{\text {end-on }}$ reactant complex. In the quartet spin state, two different structures have been calculated, both showing an end-on approach of $\mathrm{H}_{2} \mathrm{O}_{2}$ to Mn. They differ not only in the $\mathrm{Mn}-\mathrm{O}$ distances, but also in the $\mathrm{O}-\mathrm{O}$ bond lengths. In $\mathrm{RCq}^{\text {end-on }}$ the hydrogen peroxide is positioned above the metal center at large distance (Mn-O1=2.535 $\AA$, Mn-O2=3.392 $\AA$ ), whereas in $\mathrm{RC}^{\prime} \mathrm{q}^{\text {end-on }}$ one oxygen atom of $\mathrm{H}_{2} \mathrm{O}_{2}$ binds to $\mathrm{Mn}(\mathrm{Mn}-\mathrm{O} 1=2.279 \AA$, Mn-O2=3.147 $\AA$ ), leading to an increase of the $\mathrm{O}-\mathrm{O}$ bond length from $1.488 \AA$ in $\mathrm{RCq}^{\text {end-on }}$ to $1.514 \AA$ in $\mathrm{RC}^{\text {' }}$ end-on (Figure 3). In addition, in $\mathrm{RCq}^{\text {end-on }}$ the NSNSN ligand binds in a $m m f$ mode, with a terminal Py ring of the ligand occupying the axial position trans to the substrate, as found in the RCs ${ }^{\text {end-on }}$ structure. Both $\mathrm{RCq}^{\text {end-on }}$ and $\mathrm{RC}^{\prime} \mathrm{q}^{\text {end-on }}$ are less stable than the sum of the Gibbs free energies of the separate reactants by 25.1 and $34.2 \mathrm{kcal} / \mathrm{mol}$, respectively. Finally, in the doublet spin state, only one $\mathrm{RCd}^{\text {end- }}$ ${ }^{\text {on }}$ structure has been found with a $f m f$ coordination mode and an end-on coordination of hydrogen peroxide to $\mathrm{Mn}(\mathrm{Mn}-\mathrm{O} 1=2.222 \AA, \mathrm{Mn}-\mathrm{O} 2=3.154 \AA)$, and an elongated $\mathrm{O}-\mathrm{O}$ bond $(\mathrm{O}-\mathrm{O}=1.515 \AA)$, with a Gibbs free energy of $30.3 \mathrm{kcal} / \mathrm{mol}$ with respect to the sum of the Gibbs free energies of the separate reactants in their ground spin states.

It is of interest at this stage to describe the three possible spin multiplicities of the reactant complex (doublet, quartet and sextet) in terms of their spin density distribution. Values of spin densities calculated on $\mathrm{Mn}$ and the $\mathrm{N}$ and $\mathrm{S}$ donor atoms are presented in Figure 3 for $\mathrm{RCs}$ side-on, $\mathrm{RC}^{\text {' }}$ end-on and $\mathrm{RCd}^{\text {end-on }}$. The spin density distribution over the metal and the ligand in $\mathrm{RCs}^{\text {side-on }}$ is very similar to that found in the initial complex (see Figure 2 middle)): the spin density delocalizes over the Mn (3.20), the $\mathrm{N}(0.17,0.18,0.17)$ and the $\mathrm{S}(0.19,0.20)$ donor atoms, and, in addition, over the $\mathrm{O}$ atoms of the $\mathrm{H}_{2} \mathrm{O}_{2}$ substrate $(0.10,0.10)$, with approximately four unpaired electrons on $\mathrm{Mn}$ and one unpaired electron on the ligand and substrate. A less delocalized spin density distribution is found for the reactant complex in the quartet state $\mathrm{RC}^{\text {' }} \mathrm{q}^{\text {end-on }}$ with spin densities on $\mathrm{Mn}(2.03), \mathrm{N}(0.08$, $0.12,0.05)$ and $\mathrm{S}(0.05,0.07)$ and on the $\mathrm{H}_{2} \mathrm{O}_{2}$ oxygen atom bound to the metal $(0.14)$, roughly corresponding to three unpaired electrons on the $\mathrm{Mn}(\mathrm{II})$ center, and even less for the reactant complex in the doublet state $\mathrm{RCd}^{\text {end-on }}$, with a spin density on Mn of 0.83 , corresponding to one 
unpaired electron on $\mathrm{Mn}(\mathrm{II})$. Involvement of ligand spin density decreases on moving from sextet to quartet and to doublet spin states.

Starting from the above $\mathrm{RCs}^{\text {side-on }}$ reactant complex, the bond between the oxygen atoms of the hydrogen peroxide is broken and two possible scenarios can be hypothesized: one leading to a $\mathrm{Mn}(\mathrm{IV})$ dihydroxo species as the first dismutation reaction product, the other leading to a Mn(IV) oxo species, either via the formation of a dihydroxo or a monohydroxo intermediate (Scheme 1).

\section{Symmetric vs. asymmetric O-O bond breaking: formation of the intermediate species}

Firstly we analyzed the formation of the Mn dihydroxo species, which is expected to occur via a symmetric $\mathrm{O}-\mathrm{O}$ bond cleavage. The energy profile is depicted in Figure 4, whereas the transition state and the intermediate structures in the sextet, quartet and doublet spin states with relevant geometrical parameters are reported in the SI (Figure S5).

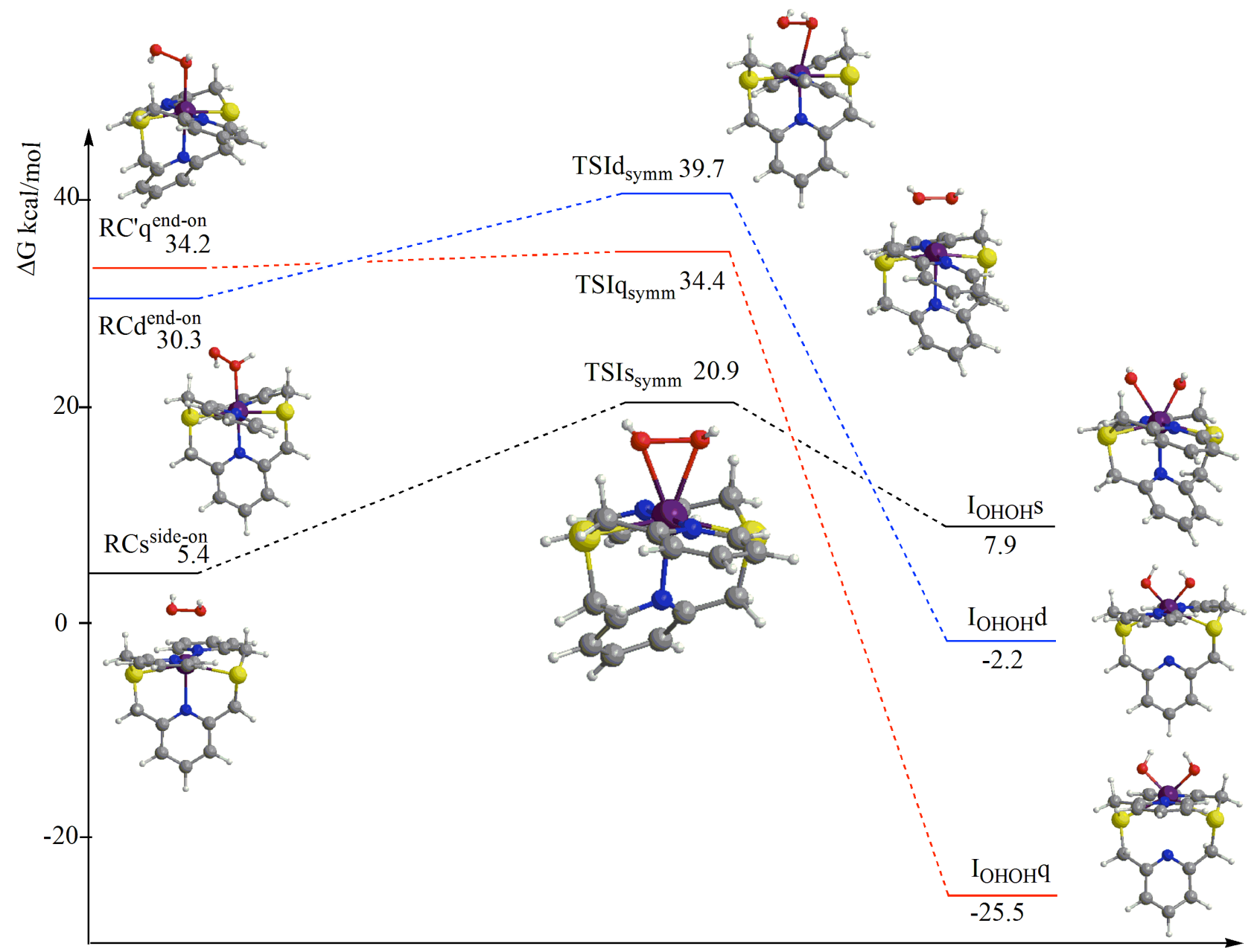




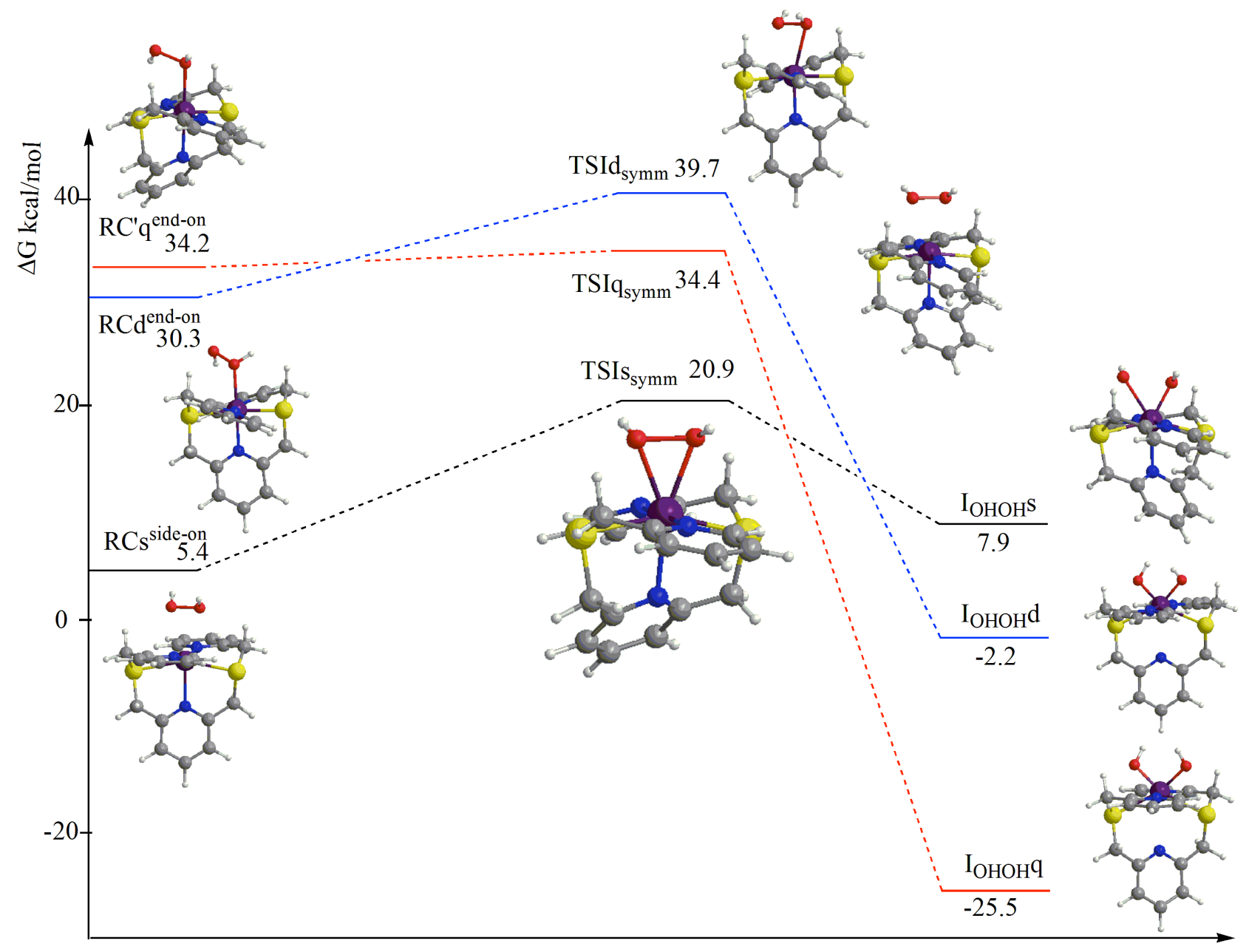

Figure 4. Energy profile of the manganese dihydroxo intermediate formation via a symmetric O-O bond breaking for sextet (black), quartet (red) and doublet (blue) spin states. The sum of the Gibbs free energies of the separate reactants $\left(\left[\mathrm{MnS}_{2} \mathrm{Py}_{3}\right]^{2+}+\mathrm{H}_{2} \mathrm{O}_{2}\right)$ is taken as the zero reference energy.

The energy profile shows that the sextet state is the lowest spin state for the reactant complexes (both $\mathrm{RCs}{ }^{\text {side-on }}$ and $\mathrm{RCs}{ }^{\text {end-on }}$ ) until the transition state $\mathrm{TSIs}_{\text {symm }}$ is reached with an activation energy barrier of $15.5 \mathrm{kcal} / \mathrm{mol}$ (20.9 $\mathrm{kcal} / \mathrm{mol}$ above the isolated reactants). The most stable O-O bond breaking process product, the dihydroxo species $\mathrm{I}_{\mathrm{OHOH}} \mathrm{x}(\mathrm{x}=\mathrm{s}, \mathrm{q}, \mathrm{d})$, is in the quartet spin state. A spin transition from the sextet to the quartet state occurs going to the dihydroxo complex $\mathrm{I}_{\mathrm{OHOH}}$. The doublet spin state profile also crosses the sextet spin state after the transition state but the corresponding dihydroxo species $\mathrm{I}_{\mathrm{OHOH}} \mathrm{d}$ is less stable than $\mathrm{I}_{\mathrm{OHOH}} \mathrm{q}$ by $23.3 \mathrm{kcal} / \mathrm{mol}$. The formation 
of $\mathrm{I}_{\mathrm{OHOH}} \mathrm{q}$ is exothermic by $25.5 \mathrm{kcal} / \mathrm{mol}$ with respect to the separate reactants.

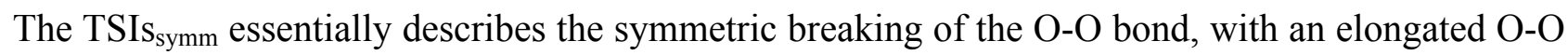
distance of $1.695 \AA$ compared to $1.452 \AA$ in the $\mathrm{RCs}^{\text {side-on }}$ complex, and with similar Mn-O distances $(\mathrm{Mn}-\mathrm{O} 1=2.293 \AA$ and $\mathrm{Mn}-\mathrm{O} 2=2.286 \AA)$. In TSIq $\mathrm{T}_{\text {symm }}$ and $\mathrm{TSId}_{\text {symm }}$ the O-O distance is shorter (1.487 $\AA$ and $1.488 \AA$, respectively) than in $\operatorname{TSIs}_{\text {symm }}(1.695 \AA)$. In the $\mathrm{I}_{\text {Онон }} \mathrm{q}$ structure two symmetric metal-hydroxo bonds are formed $(\mathrm{Mn}-\mathrm{O} 1=\mathrm{Mn}-\mathrm{O} 2=1.830 \AA)$ at the expense of the Mn-N pyridine bond trans to the two hydroxo ligands which elongates significantly $(\mathrm{Mn}-\mathrm{N}=2.917$ $\AA$ vs. $\mathrm{Mn}-\mathrm{N}=2.191 \AA$ in $\mathrm{RCq}^{\text {end-on }}$ ). As a result, the $\mathrm{N}$-pyridine trans to the two hydroxyl groups is no longer bound to the manganese center, which preserves the six-coordination, in a trigonal prismatic-like geometry. This peculiar feature is found for both $\mathrm{I}_{\mathrm{OHOH}} \mathrm{q}$ and $\mathrm{I}_{\mathrm{OHOH}} \mathrm{d}$, but not for $\mathrm{I}_{\mathrm{OHOH}} \mathrm{S}$. In the $\mathrm{I}_{\mathrm{OHOH}} \mathrm{S}$ geometry the two hydroxo moieties are not symmetrically bound to $\mathrm{Mn}(\mathrm{Mn}-$ $\mathrm{O} 1=1.918 \AA, \mathrm{Mn}-\mathrm{O} 2=2.311 \AA$ ) and the characteristic position of the axial Py ring stacking parallel to one of the equatorial Py rings is observed (note that $\mathrm{I}_{\mathrm{OHOH}} \mathrm{S}$ is geometrically similar to the TSIs $_{\text {symm }}$ and RC'q ${ }^{\text {end-on }}$ structures).

This finding suggests that the formation of the Mn dihydroxo species could take place alternatively via an asymmetric $\mathrm{O}-\mathrm{O}$ bond cleavage of the $\mathrm{H}_{2} \mathrm{O}_{2}$. The energy profile for this process is depicted in Figure 5. 


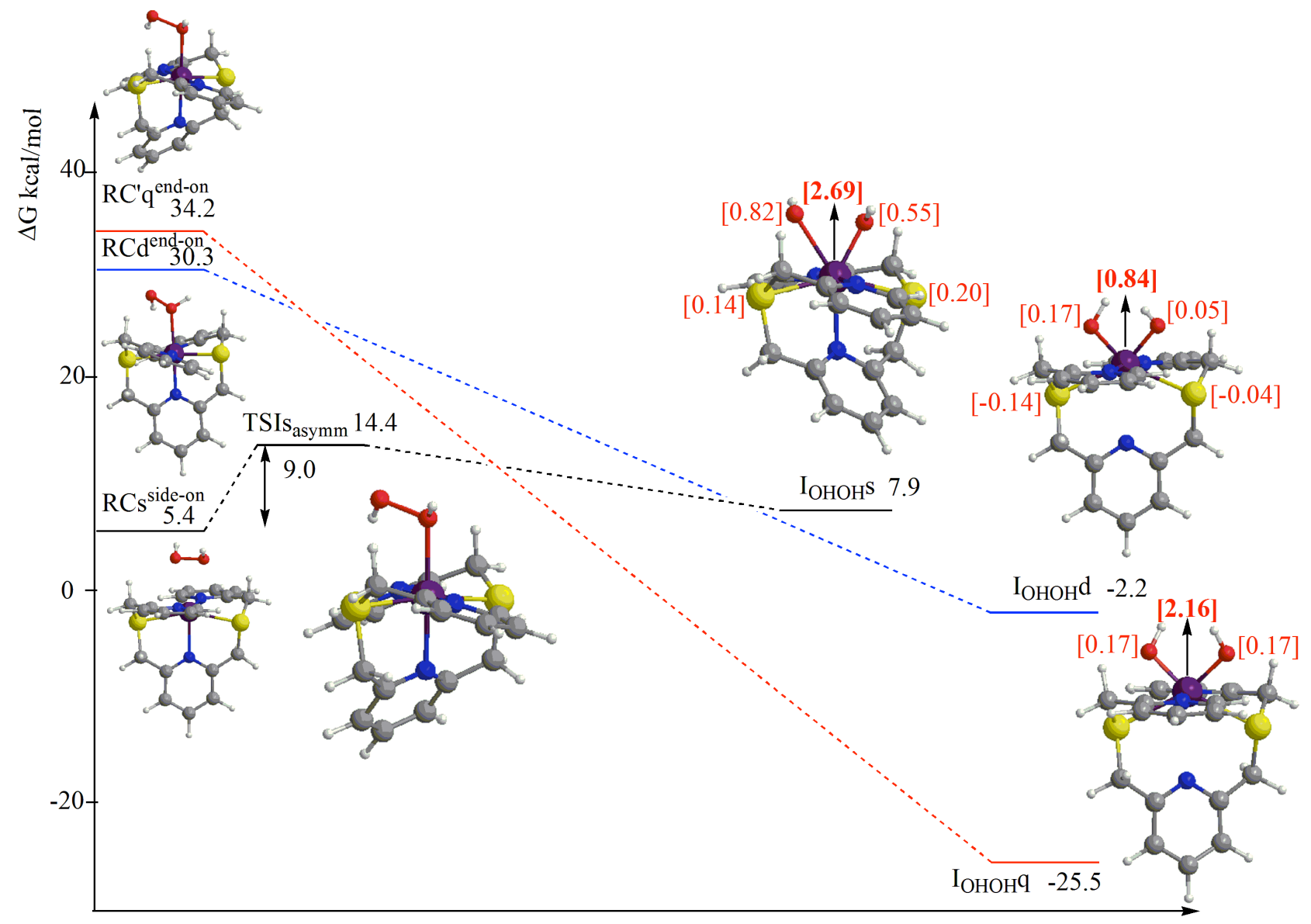

Figure 5. Energy profile of the manganese dihydroxo intermediate formation via an asymmetric OO bond breaking for sextet (black), quartet (red) and doublet (blue) spin states. The sum of the Gibbs free energies of the separate reactants $\left(\left[\mathrm{MnS}_{2} \mathrm{Py}_{3}\right]^{2+}+\mathrm{H}_{2} \mathrm{O}_{2}\right)$ is taken as the zero reference energy. Values in square brackets are spin densities (based on Multiple Derived Charges (MDC-q) analysis) calculated on $\mathrm{Mn}, \mathrm{S}$ and $\mathrm{O}$ atoms.

Similar to Figure 4, the energy profile shows that the sextet state is the lowest spin state for the reactant complex $\mathrm{RCs}^{\text {end-on }}$ until the transition state $\mathrm{TSIs}_{\text {asymm, }}$ lying $14.4 \mathrm{kcal} / \mathrm{mol}$ above the separate reactants, is reached with an activation energy barrier of only $9.0 \mathrm{kcal} / \mathrm{mol}$. In the quartet and doublet energy profiles no transition states have been found, indicating that the asymmetric O- 
O bond breaking occurs immediately from the corresponding reactant complexes. A spin crossover from the sextet to the quartet state occurs on the path to the most stable dihydroxo complex $\mathrm{I}_{\mathrm{OHонq}}$.

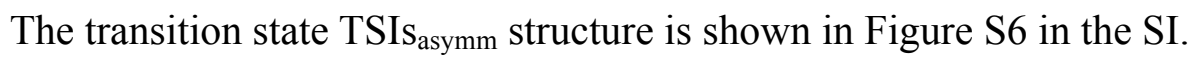

From these results, we conclude that the $\mathrm{O}-\mathrm{O}$ bond cleavage in $\mathrm{H}_{2} \mathrm{O}_{2}$ leading to the Mn dihydroxo species is highly exothermic $(\Delta \mathrm{G}=-25.5 \mathrm{kcal} / \mathrm{mol}$ with respect to the free reactants) and it takes place asymmetrically, through a transition state located on the sextet spin state followed by a spin crossover from the sextet to the quartet spin state, with a relatively low activation barrier $(9.0$ $\mathrm{kcal} / \mathrm{mol}$ ). The removal of the axial pyridine ligand is a crucial factor for stabilizing the dihydroxo species. A special role of the axial ligand has also been reported in the literature, for instance, the O$\mathrm{O}$ bond activation in acylperoxo complexes of [(Salen)Mn(III)L], ${ }^{67}$ the $\mathrm{H}_{2} \mathrm{O}_{2}$ activation by an $\mathrm{Mn}(\mathrm{III})$ corrolazine complex, ${ }^{68}$ and the nucleophilic reactivity of a nonheme manganese(III)-peroxo complex. ${ }^{69}$

Asymmetric $\mathrm{O}-\mathrm{O}$ bond cleavage of $\mathrm{H}_{2} \mathrm{O}_{2}$ could also lead to the generation of the Mn monohydroxo species. The energy profile for the formation of the monohydroxo intermediate is shown in Figure 6, where the monohydroxo intermediate structures are in the sextet, quartet and doublet spin states. The main geometrical parameters are displayed in Figure S7 in the SI. 


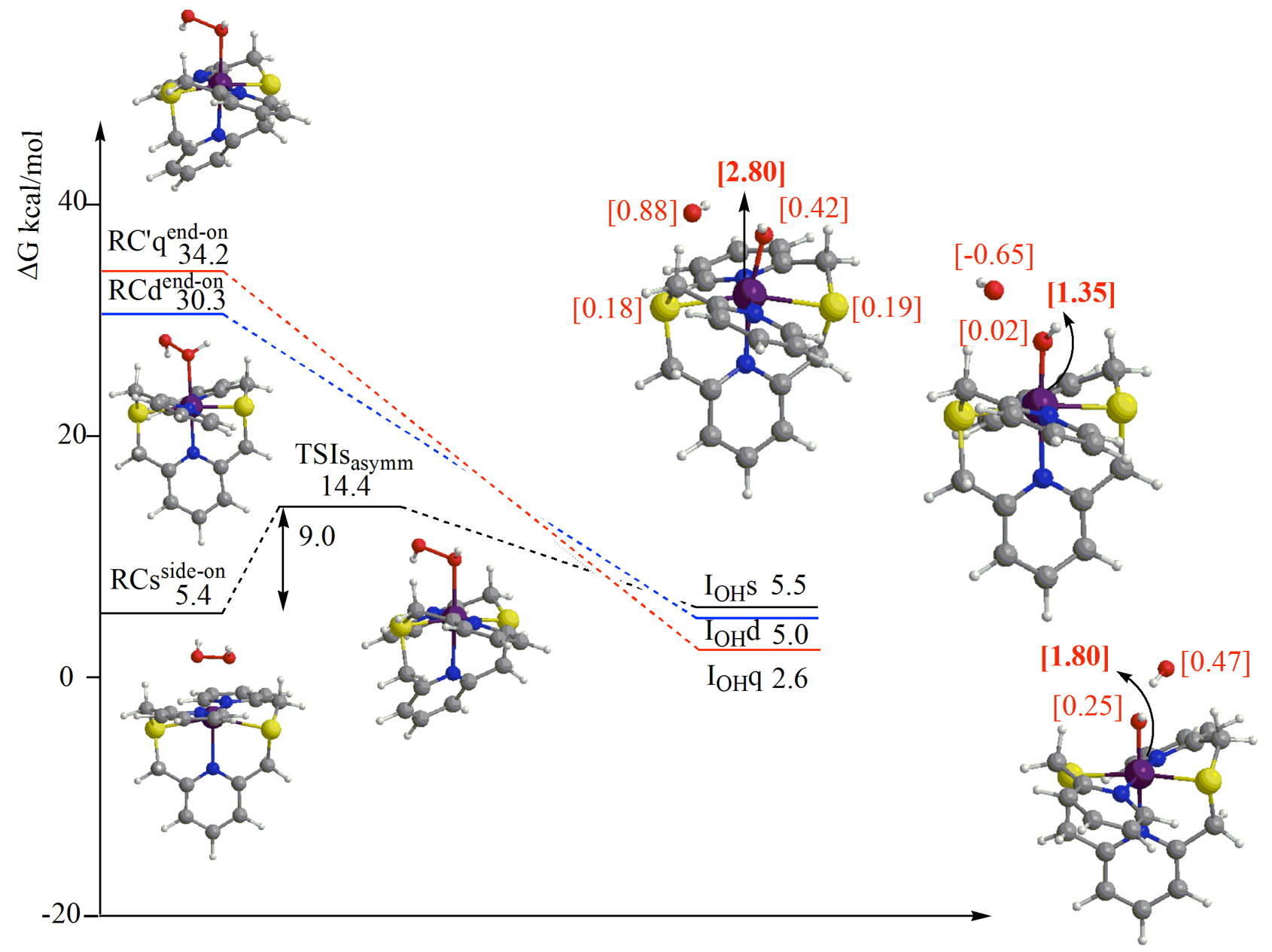

Figure 6. Energy profile of the manganese monohydroxo intermediate formation reaction for sextet (black), quartet (red) and doublet (blue) spin states. The sum of the Gibbs free energies of the separate reactants $\left(\left[\mathrm{MnS}_{2} \mathrm{Py}_{3}\right]^{2+}+\mathrm{H}_{2} \mathrm{O}_{2}\right)$ is taken as the zero reference energy. Values in square brackets are spin densities (based on Multiple Derived Charges (MDC-q) analysis) calculated on $\mathrm{Mn}, \mathrm{S}$ and $\mathrm{O}$ atoms.

The energy profiles show that the sextet state is always the lowest spin state. The O-O bond breaking leads to the same transition state TSIs $\mathrm{s}_{\text {asymm }}$ as shown in Figures 5 and S6 with the same activation energy of $9.0 \mathrm{kcal} / \mathrm{mol}(14.4 \mathrm{kcal} / \mathrm{mol}$ above the separate reactants). This finding substantiates both the occurrence of the $\mathrm{O}-\mathrm{O}$ bond breaking in the sextet spin state and the 
formation of the dihydroxo complex due to a geometrical rearrangement process that triggers the spin crossover from sextet to quartet. In the monohydroxo intermediate formation, the sextet spin state profile remains at lower energy than the doublet and quartet spin states during the major part of the reaction. Both the doublet and the quartet are very reactive paths leading to the $\mathrm{Mn}$ monohydroxo species formation in a barrierless process. The doublet and quartet monohydroxo complexes, $\mathrm{I}_{\mathrm{OH}} \mathrm{d}$ and $\mathrm{I}_{\mathrm{OH}} \mathrm{q}$, are more stable than $\mathrm{I}_{\mathrm{OH}} \mathrm{S}$ by 0.5 and $2.9 \mathrm{kcal} / \mathrm{mol}$, respectively, with the quartet $\mathrm{I}_{\mathrm{OH}} \mathrm{q}$ being the most stable Mn monohydroxo species, which indicates that a spin crossover from the sextet to the quartet should occur at the vicinity of the final product geometry. Note that the octahedral geometry is retained in $\mathrm{I}_{\mathrm{OH}} \mathrm{q}$. The geometry of $\mathrm{I}_{\mathrm{OH}} \mathrm{S}$ shows that the $\mathrm{OH}$ in the second coordination sphere is not at a very large distance from $\mathrm{Mn}(\mathrm{Mn}-\mathrm{OH}=2.955 \AA)$. A direct comparison between Figures 5 and 6 shows that although the activation energy barrier for both the quartet monohydroxо $\mathrm{I}_{\mathrm{OH}} \mathrm{q}$ and dihydroxо $\mathrm{I}_{\mathrm{OHOH}} \mathrm{q}$ formation is the same $(9.0 \mathrm{kcal} / \mathrm{mol})$, since the same TSIs $_{\text {asymm }}$ is involved, the quartet monohydroxo $\mathrm{I}_{\mathrm{OH}} \mathrm{q}$ formation reaction is endothermic by

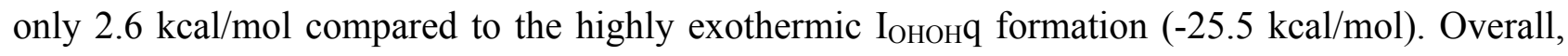
these results support the Mn dihydroxo species in the quartet state as the thermodynamically favored intermediate.

The O-O bond breaking in $\mathrm{H}_{2} \mathrm{O}_{2}$ induced by $\left[\mathrm{MnS}_{2} \mathrm{Py}_{3}\right]^{2+}$ complex can be analyzed in detail by comparing the electronic structures of RCs ${ }^{\text {side-on }}$ and $\mathrm{I}_{\mathrm{OH}} \mathrm{S}$, as depicted by the simplified bonding scheme in Figure 7, where evolution of the Mn 3d orbitals and $\sigma^{*} \mathrm{H}_{2} \mathrm{O}_{2}$ orbital from $\mathrm{RCs}$ side-on to $\mathrm{I}_{\mathrm{OH}} \mathrm{s}$ can be followed. 


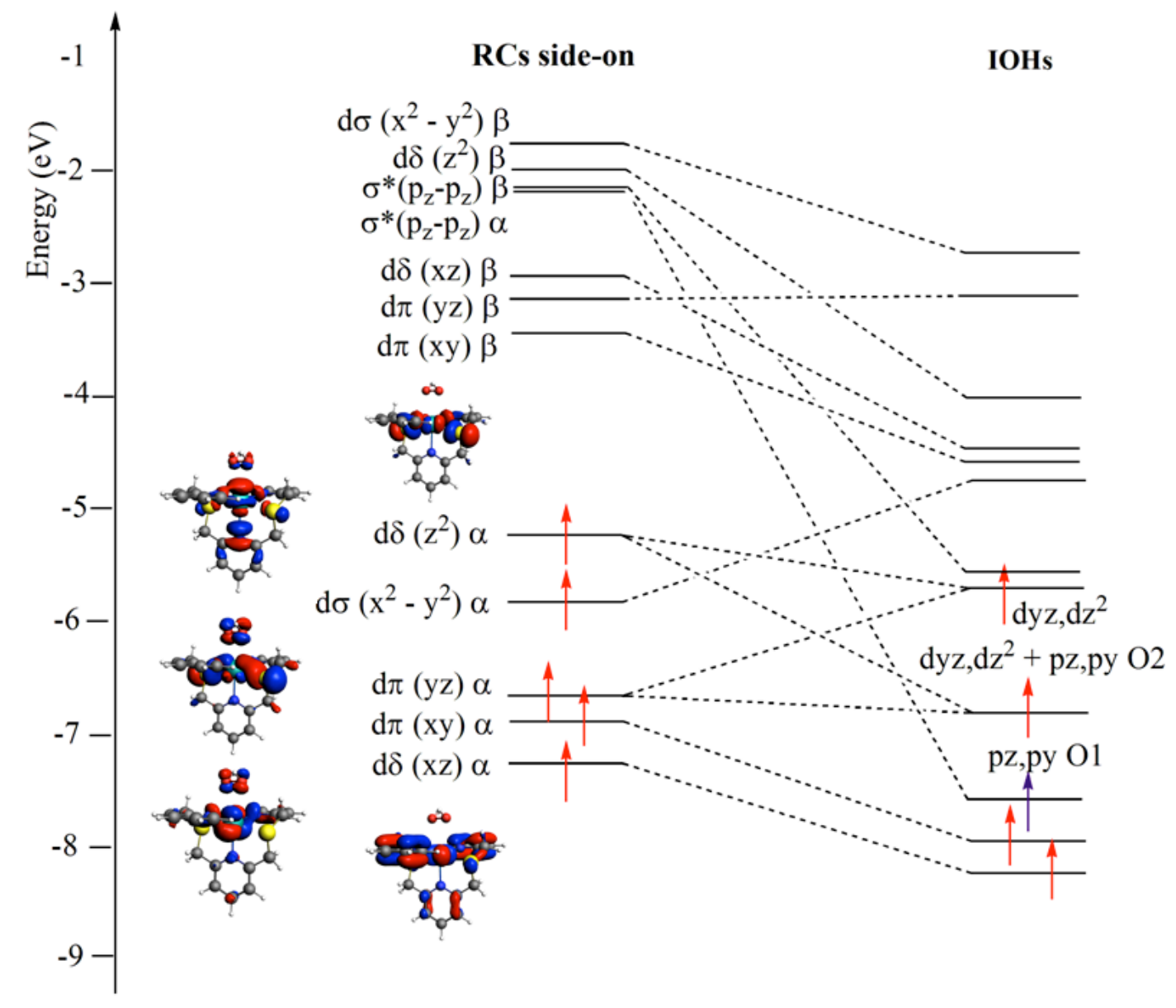

Figure 7. Simplified bonding scheme for the $\mathrm{H}_{2} \mathrm{O}_{2}$ interactions in $\left[\mathrm{MnS}_{2} \mathrm{Py}_{3}\right]^{2+}$ leading to $\mathrm{I}_{\mathrm{OH}} \mathrm{S}$. O1 denotes oxygen atom of non-coordinating $\mathrm{OH}, \mathrm{O} 2$ is the oxygen atom of the $\mathrm{OH}$ bonded to $\mathrm{Mn}$. The $\sigma, \pi$ and $\delta$ symmetry labels refer to the $\left[\mathrm{MnS}_{2} \mathrm{Py}_{3}\right]^{2+}$ axis system (the axial $\mathrm{N}$ atom ligand and the incoming $\mathrm{H}_{2} \mathrm{O}_{2}$ substrate lies along the $\mathrm{y}$ axis, the equatorial $\mathrm{S}$ atoms ligand along the $\mathrm{z}$ axis, and the equatorial $\mathrm{N}$ atoms ligand along the $\mathrm{x}$ axis).

In Figure 7 we see that the energy of the five Mn 3d singly occupied $\alpha$-spin orbitals is lower than that of the empty $\mathrm{H}_{2} \mathrm{O}_{2} \sigma^{*}$ ( $\alpha$ - and $\beta$-spin) orbitals in $\mathrm{RCs}^{\text {side-on }}$. In the Mn $3 \mathrm{~d}$ singly occupied $\alpha$-spin set, the lowest $d \delta(x z)$ has mainly metal character, whereas $d \pi(x y)$ and $d \pi(y z)$ are pushed up in energy by antibonding interaction with filled $\mathrm{H}_{2} \mathrm{O}_{2} \pi^{*}$ orbitals (with a contribution of $6 \%$, and $12 \%$, respectively). Remarkable $\mathrm{S}$ ligand atoms character can be found in $\mathrm{d} \pi(\mathrm{yz})\left(16 \% 3 \mathrm{p}_{\mathrm{z}} \mathrm{S}+15 \% 3 \mathrm{p}_{\mathrm{z}}\right.$ 
S) and $d \delta\left(z^{2}\right)\left(11 \% 3 p_{z} S+11 \% 3 p_{z} S\right)$, while $d \sigma\left(x^{2}-y^{2}\right)$ exhibits axial $N$ ligand (antibonding) contribution $\left(12 \% 2 \mathrm{p}_{\mathrm{y}} \mathrm{N}\right)$. The electronic structure of $\mathrm{RCs}^{\text {side-on }}$ accounts for the spin density distribution described in the previous section. Evolution of $\mathrm{RCs}^{\text {side-on }}$ towards $\mathrm{I}_{\mathrm{OH}} \mathrm{s}$ leads to the electronic structure also depicted in Figure 7. In $\mathrm{I}_{\mathrm{OH}} \mathrm{S}$ one of the five $\alpha$-spin unpaired electrons in $\mathrm{RCs}^{\text {side-on }}$ now occupies a $2 \mathrm{p}_{\mathrm{z}} / 2 \mathrm{p}_{\mathrm{y}}$ hybrid orbital localized on the oxygen atom of the noncoordinating $\mathrm{OH}\left(\mathrm{O} 1\right.$, blue arrow in Figure 7), and one electron a bonding $\mathrm{Mn} d \mathrm{dz} / \mathrm{dz}^{2}-\mathrm{O} 22 \mathrm{p}_{\mathrm{z}} / 2 \mathrm{p}_{\mathrm{y}}$ orbital (O2 denotes the oxygen atom of the bonded $\mathrm{OH})$. The remaining three $\alpha$-spin unpaired electrons are mainly localized on Mn 3d orbitals. A total of "one electron and half" (roughly two electrons) is transferred from $\mathrm{Mn}$ to $\mathrm{H}_{2} \mathrm{O}_{2}$ to form a non-coordinating $\mathrm{OH}$ radical and a bond order of $1 / 2$ between $\mathrm{Mn}$ and the second $\mathrm{OH}$. Very interestingly, the empty $\beta$-spin $2 p_{z} / 2 p_{y}$ counterpart of the $\mathrm{O} 1$ orbital represents the LUMO and it is very close in energy to the singly occupied $\alpha$-spin Mn $\mathrm{dyz} / \mathrm{dz}^{2}$ (also containing substantial ligand $\mathrm{S}$ atom contributions) HOMO $(\Delta \mathrm{E}=0.11 \mathrm{eV})$. A spin flip transition can easily occurs where the $M n d y z / d z^{2} \alpha$-spin electron transfers to the $012 p_{z} / 2 p_{y}$ orbital with a $\beta$-spin, accounting for a spin crossover from sextet to quartet in the complex. We should notice that the $\alpha$-spin electron undergoing the transition is partially delocalized on the $\mathrm{S}$ ligand atoms, which experience then a loss of $\alpha$-spin density in spin crossover. Occupation of the O1 $2 \mathrm{p}_{\mathrm{z}} / 2 \mathrm{p}_{\mathrm{y}}$ orbital with the $\beta$-spin electron allows bonding of the non-coordinating $\mathrm{OH}$ with $\mathrm{Mn}$, coupled with a geometry rearrangement resulting in $\mathrm{I}_{\mathrm{OHOH}} \mathrm{q}$, where the bond order between the $\mathrm{Mn}$ and each $\mathrm{OH}$ can be considered $1 / 2$.

The nature of the dihydroxo and monohydroxo species is clearly visualized in the spin density distribution. In $\mathrm{I}_{\mathrm{OHOH}}$ in the sextet spin state, roughly three unpaired electrons localize on the metal (2.69), one unpaired electron on one oxygen atom of $\mathrm{H}_{2} \mathrm{O}_{2}(0.82)$, and 1one unpaired electron delocalizes on $\mathrm{S}$ donor atoms of the ligand $(0.20,0.14)$ and on the other oxygen atom of $\mathrm{H}_{2} \mathrm{O}_{2}$ bonded to $\mathrm{Mn}(0.55)$, which leads to an overall electronic structure in the sextet state and to a formal high-spin $\mathrm{Mn}(\mathrm{IV})$ (five $\alpha$-spin unpaired electrons on the complex with roughly three unpaired electrons on $\mathrm{Mn}$ ) (see Fig.5). Interestingly, in the sextet state the spin density distribution 
in the intermediate $\mathrm{I}_{\mathrm{OH}}$ is very similar to that in $\mathrm{I}_{\mathrm{OHOH}}$ (compare Figure 5 and 6 ), thus suggesting that the $\mathrm{H}_{2} \mathrm{O}_{2}$ dissociation in the sextet spin state invariably leads to a non-coordinating $\mathrm{OH}$ radical. A different situation is found in the quartet spin state. In the $\mathrm{I}_{\mathrm{OHOH}}$, three unpaired electrons are delocalized over the Mn atom (2.16) and the two oxygen atoms of the two hydroxyl moieties $(0.17$ and 0.17 ), a spin distribution roughly corresponding to a formal $\mathrm{Mn}(\mathrm{IV}$ ) (about three unpaired electrons on $\mathrm{Mn}$, with two $\alpha$ - and $\beta$-spin electrons each involved in the bonding of one $\mathrm{OH}$ group) (see Fig.5 and 7). In $\mathrm{I}_{\mathrm{OH}}$ the spin density on $\mathrm{Mn}$ and hydroxyl bonded to it is close to two, which can be similarly assigned to a Mn(IV), with roughly the third unpaired electron localized on the oxygen atom of the non-coordinating $\mathrm{OH}(0.47)$ (Fig. 6). Notably, $\mathrm{I}_{\mathrm{OH}}$ in the quartet state bears a much less radical character than that in $\mathrm{I}_{\mathrm{OH}}$ in the sextet spin state. Finally, in the $\mathrm{I}_{\mathrm{OHOH}}$ in the doublet state, one unpaired electron is delocalized on the Mn center $(0.84)$ and on one oxygen atom of an hydroxyl group (0.17) (see Fig.5), whereas in $\mathrm{I}_{\mathrm{OH}}$ an antiferromagnetically coupled spin between the non-coordinating $\mathrm{OH}$ oxygen atom (about one beta-spin unpaired electron) and $\mathrm{Mn}$ (two alpha-spin unpaired electrons) has been found (see Fig. 6).

\section{Formation of the Mn(IV) oxo species: exploring the ping-pong reaction channel}

Finally we investigated the formation of the $\mathrm{Mn}(\mathrm{IV})$ oxo species plus a water molecule as the first dismutation products via the $\mathrm{I}_{\mathrm{OH}}$ and $\mathrm{I}_{\mathrm{OHOH}}$ intermediates calculated for each spin state. The energy profiles are shown in Figure 8 and the transition states and intermediate structures in the sextet, quartet and doublet spin states together with the main geometrical parameters are reported in Figure S8 in the SI. 


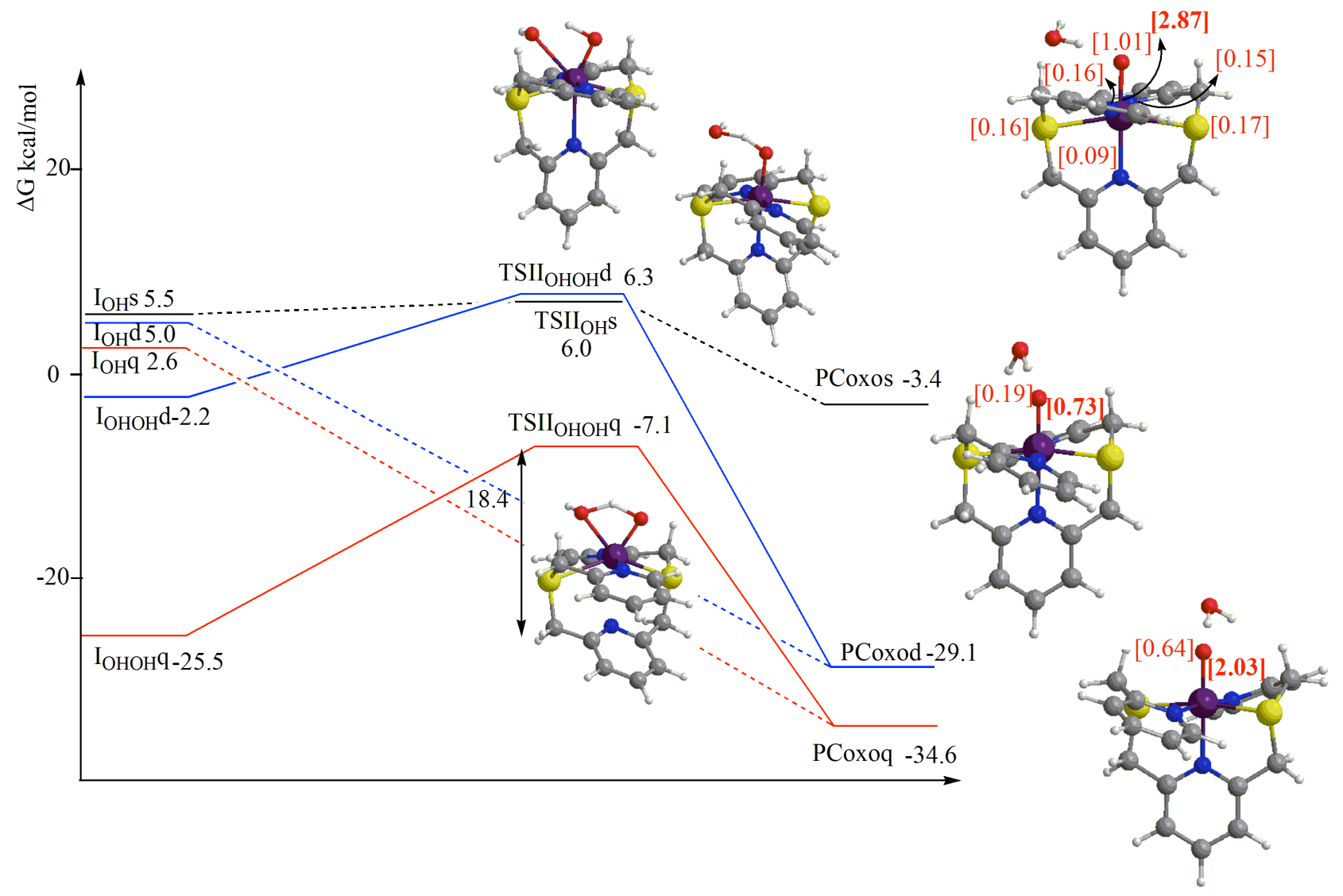

Figure 8. Energy profile for the manganese oxo intermediate formation from the manganese monohydroxo intermediate for sextet (black), and from the manganese dihydroxo/monohydroxo intermediate for quartet (red) and doublet (blue) spin states. Dashed lines connect species involving monohydroxo intermediates; solid lines connect species involving dihydroxo intermediates. Values in square brackets are spin densities (based on Multiple Derived Charges (MDC-q) analysis) calculated on $\mathrm{Mn}, \mathrm{S}, \mathrm{N}$ and $\mathrm{O}$ atoms.

Starting from the Mn dihydroxo intermediates in the sextet $\left(\mathrm{I}_{\mathrm{OHOH}} \mathrm{s}\right)$, quartet $\left(\mathrm{I}_{\mathrm{OHOH}} \mathrm{q}\right)$ and doublet ( $\left.\mathrm{I}_{\mathrm{OHOH}} \mathrm{d}\right)$ spin states, the formation of the corresponding Mn oxo species plus a water molecule is induced by approaching a hydrogen atom of one $\mathrm{OH}$ group to the vicinal oxygen atom of the second $\mathrm{OH}$ group. During this process, in the sextet spin state, one of the coordinated $\mathrm{OH}$ groups readily 
dissociates from Mn leading to the more stable monohydroxo species, thus confirming that the dihydroxo species is not a viable intermediate in this spin state. Therefore, for the sextet spin state profile we start from $\mathrm{I}_{\mathrm{OH}} \mathrm{s}$. From the monohydroxo intermediates in the sextet $\left(\mathrm{I}_{\mathrm{OH}} \mathrm{s}\right)$, quartet $\left(\mathrm{I}_{\mathrm{OH}} \mathrm{q}\right)$ and doublet $\left(\mathrm{I}_{\mathrm{OH}} \mathrm{d}\right)$ spin state, the hydrogen transfer is achieved by approaching the hydrogen atom of the $\mathrm{OH}$ group bound to $\mathrm{Mn}$ towards the non-coordinating hydroxide. The formation of the $\mathrm{Mn}$ oxo species plus a water molecule via the monohydroxo intermediate would be a barrierless process in the quartet and doublet spin states and it requires only $0.5 \mathrm{kcal} / \mathrm{mol}$ in the sextet. However, the energy profiles show that the quartet state (via both the $\mathrm{I}_{\mathrm{OHOH}}$ and $\mathrm{I}_{\mathrm{OH}}$ intermediates) is always the lowest spin state and the sextet is the highest.

For the ping-pong mechanism via the $\mathrm{Mn}(\mathrm{IV})$ dihydroxo intermediate, a relatively low activation barrier is calculated on the doublet spin state $\left(8.5 \mathrm{kcal} / \mathrm{mol}\right.$ with respect to $\left.\mathrm{I}_{\mathrm{OHOH}} \mathrm{d}\right)$, leading to a very stable product $\mathrm{PC}_{\text {oxod }}(29.1 \mathrm{kcal} / \mathrm{mol}$ below the separate reactants $)$, but the excitation of the $\mathrm{I}_{\mathrm{OHOH}}$ complex from the quartet to the doublet state would require $23.3 \mathrm{kcal} / \mathrm{mol}$. The transition state for the hydrogen migration is calculated on the quartet spin state (TSII $\mathrm{OHOH}_{\text {) }}$ with an activation barrier of $18.4 \mathrm{kcal} / \mathrm{mol}$. The $\mathrm{PC}_{\text {oxoq }}$ product is more stable than the separate reactants by $34.6 \mathrm{kcal} / \mathrm{mol}$. This reaction is exothermic $\left(\mathrm{PC}_{\text {охоq }}\right.$ is more stable than $\mathrm{I}_{\mathrm{OHOH}} \mathrm{q}$ by $\left.9.1 \mathrm{kcal} / \mathrm{mol}\right)$ but the activation energy barrier is relatively high $(18.4 \mathrm{kcal} / \mathrm{mol})$ and this would represent the rate-determining step for the whole first dismutation reaction leading to the Mn oxo species. Therefore, the intermediate $\mathrm{I}_{\mathrm{OHOH}} \mathrm{q}$ can be considered as an "energetic trap" on this reaction path, making the ping-pong mechanism much less efficient than the pathway via monohydroxo intermediates.

These results clearly suggest that the first dismutation reaction with the $\left[\mathrm{MnS}_{2} \mathrm{Py}_{3}\right]^{2+}$ complex cannot be simply described with the classical ping-pong mechanism leading to the formation of a Mn oxo intermediate and a water molecule, but an alternative one-step mechanism, leading to the formation of a stable Mn dihydroxo intermediate via a spin crossover from a sextet to a quartet spin state is also viable. Mn dihydroxo complexes are rare but not unknown in the literature. For example, a robust $\mathrm{Mn}(\mathrm{IV})$ dihydroxo complex with a rigid, cross-bridged, cyclam ligand, 4,11- 
dimethyl-1,4,8,11-tetraazabicyclo[6.6.2]hexadecane, $\left[\mathrm{Mn}\left(\mathrm{Me}_{2} \mathrm{EBC}\right)(\mathrm{OH})_{2}\right]^{2+}$, has been reported by Busch and coworkers ${ }^{70}$ as the first thoroughly characterized monomeric Mn(IV) complex containing a pair of hydroxo ligands constituting the activated form of the oxidation catalyst with hydrogen abstracting ability. Evidence for a mononuclear Mn(IV) complex with two hydroxide ligands in a cis arrangement has been reported by Costas and coworkers. ${ }^{71}$ The authors show the ability of the $\mathrm{Mn}(\mathrm{IV})$ complex $\left[\mathrm{Mn}\left({ }^{\mathrm{H}, \mathrm{Me}} \mathrm{Pytacn}\right)(\mathrm{OH})_{2}\right]^{2+}$ (Pytacn = 1-(2-pyridylmethyl)-4,7dimethyl-1,4,7-triazacyclononane) to abstract a hydrogen atom from $\mathrm{C}-\mathrm{H}$ bonds of several substrates. Further evidence supporting a mononuclear $\mathrm{Mn}(\mathrm{II})$ catalyst for $\mathrm{H}_{2} \mathrm{O}_{2}$ disproportionation was obtained by Smith and coworkers ${ }^{72)}$ with a pyridinophane complex $\left[\mathrm{Mn}\left(\mathrm{Py}_{2} \mathrm{~N}_{2}\right)\left(\mathrm{H}_{2} \mathrm{O}\right)_{2}\right]^{2+}$. A catalytic cycle consistent with experimental data was proposed which involves the formation of a hydroperoxo intermediate $\left[\mathrm{Mn}\left(\mathrm{Py}_{2} \mathrm{~N}_{2}\right)\left(\mathrm{H}_{2} \mathrm{O}\right)\left(\mathrm{O}_{2} \mathrm{H}\right)\right]^{+}$with $\mathrm{H}_{2} \mathrm{O}$ and $\mathrm{O}_{2} \mathrm{H}^{-}$in a cis arrangement.

The reactivity of the Mn mono oxo intermediate with the second $\mathrm{H}_{2} \mathrm{O}_{2}$ substrate molecule in the second dismutation reaction can be predicted on the basis of the electronic structure and spin density distribution in $\mathrm{PC}_{\text {Ioxo }}$ species. It is instructive to compare the electronic structures of $\mathrm{PC}_{\mathrm{oxos}}$ and $\mathrm{PC}_{\text {oxoq, }}$ which are depicted as simplified $\mathrm{MO}$ diagrams in terms of basic bonding pattern of $\mathrm{Mn}$ $\mathrm{O}$ in Figure 9. The two complexes feature Mn(IV)-oxo units in a octahedral geometry with the same ligand and consequently we can understand the variations in promoting hydrogen-abstraction from $\mathrm{H}_{2} \mathrm{O}_{2}$ on the basis of the exchange-field strength depending on the spin state. ${ }^{73}$

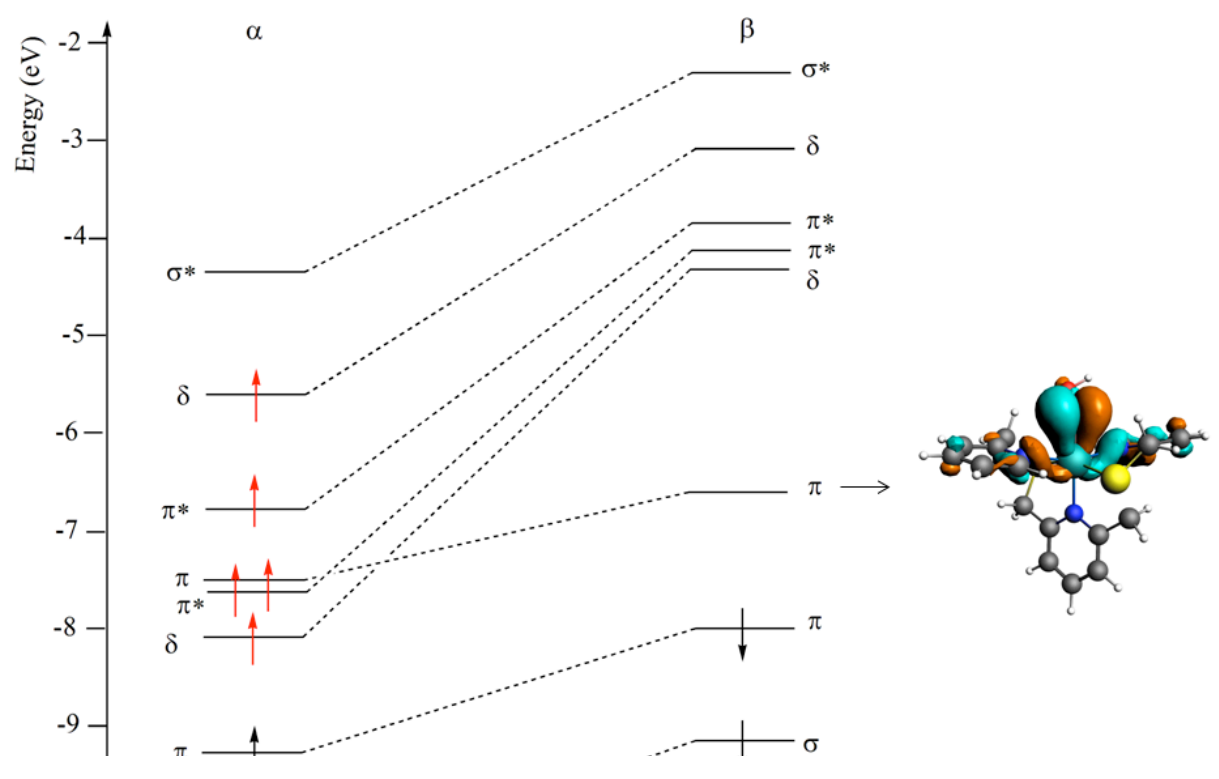




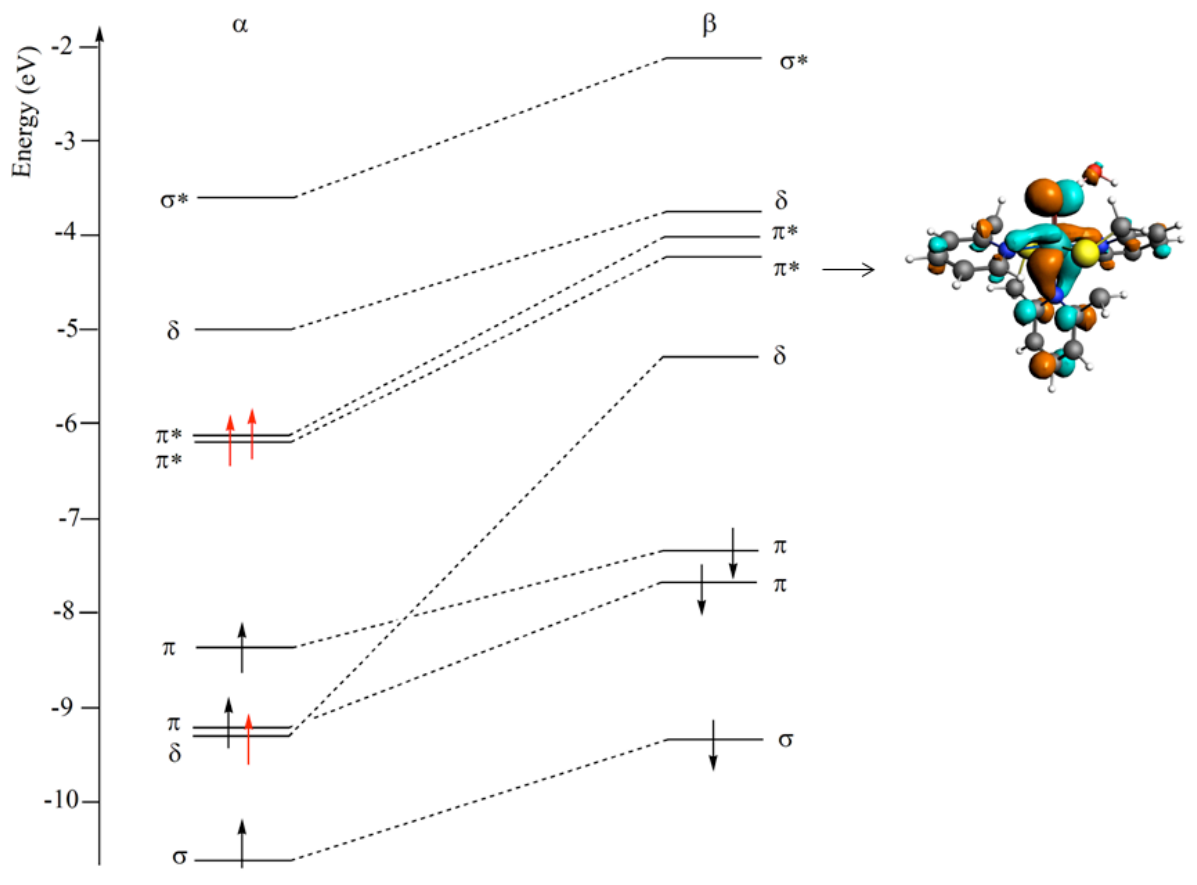

Figure 9. Valence orbital level diagram for the $\mathrm{PC}_{\text {Ioxo }}$ species: top) sextet spin state $\left(\mathrm{PC}_{\mathrm{oxos}}\right)$; bottom) quartet spin state $\left(\mathrm{PC}_{\mathrm{oxoq}}\right)$. Only $\mathrm{Mn}-\mathrm{O}$ states are illustrated for simplicity. Unpaired electrons are represented with red arrows.

As illustrated in ref.s ${ }^{74,75}$, the basic bonding pattern of a M-O unit is similar to that of dioxygen: there are three occupied bonding orbitals $\left(\mathrm{pd} \sigma, \operatorname{pd} \pi_{\mathrm{x}}\right.$ and $\mathrm{pd} \pi_{\mathrm{z}}$, see the black up and down arrows in the $\alpha$ - and $\beta$-spin orbitals in Figure 9), and there are two unpaired electrons (red arrows) in the antibonding $d p \pi^{*}$ and $d p \pi_{z}^{*}$. Notation $p d \sigma$ and $p d \pi$ is used here for the low-lying bonding combinations of $\mathrm{O} 2 \mathrm{p}$ with $\mathrm{Mn} 3 \mathrm{p}$ orbitals, which are nominally "oxygen levels" (leading $\mathrm{p}$ contribution), whereas $\mathrm{dp} \sigma^{*}$ and $\mathrm{dp} \pi^{*}$ denote the higher-lying antibonding orbitals, which are 
nominally " $\mathrm{d}$ orbitals" (leading $\mathrm{d}$ contribution). The difference of the $\mathrm{MnO}^{2+}$ electronic structure with the basic $\mathrm{O}_{2}$-type bonding scheme is in the presence of the two nonbonding $3 \mathrm{~d}$ orbitals on $\mathrm{Mn}$ of $\delta$ symmetry with respect to the $\mathrm{Mn}-\mathrm{O}$ axis (here the $\mathrm{y}$ axis), the $\mathrm{dz}^{2}$ and $\mathrm{dxz}$ orbitals. They contain two unpaired electrons (all unpaired electrons are denoted with red arrows) which, with the two unpaired electrons in the $\pi^{*}$ levels, add up to four. The fifth unpaired electron leading to the sextet spin state resides in the bonding $\mathrm{pd} \pi_{\mathrm{x}}$ (Figure 9 top)). The sextet spin configuration (pd $\sigma$ $\alpha)^{1}(\operatorname{pd} \sigma \beta)^{1}\left(\operatorname{pd} \pi_{z} \alpha\right)^{1}\left(\operatorname{pd} \pi_{z} \beta\right)^{1}\left(\operatorname{pd} \pi_{x} \alpha\right)^{1}\left(\operatorname{pd} \pi_{x} \beta\right)^{0}\left(\mathrm{dp} \pi^{*}{ }_{x} \alpha\right)^{1}\left(\mathrm{dp} \pi^{*}{ }_{z} \alpha\right)^{1}\left(\mathrm{dz}^{2} \alpha\right)^{1}(\mathrm{dxz} \alpha)^{1}$ corresponds to a $\mathrm{Mn}-\mathrm{O}$ bond order of $3 / 2$. Note that this electronic configuration is in an excited state, with the empty $\operatorname{pd} \pi_{\mathrm{x}} \beta$ ( $\pi$ bonding) orbital lying at lower energy than that of the singly occupied $\mathrm{dz}^{2} \alpha(\delta$ nonbonding orbital). The excited-state reactivity model has been previously proposed in the literature for understanding hydrogen-atom transfer for $\left[\mathrm{Mn}^{\mathrm{IV}}(\mathrm{O})(\mathrm{N} 4 \mathrm{py})\right]^{2+}(\mathrm{N} 4 \mathrm{py}=\mathrm{N}, \mathrm{N}-\mathrm{bis}(2-$ pyridylmethyl)-N-bis(2-pyridyl)methylamine pentadentate ligand) and related $\mathrm{Mn}^{\mathrm{IV}}$-oxo complexes. $^{76-78}$ This high-spin configuration reverts to the quartet spin configuration (pdo $\left.\alpha\right)^{1}(\operatorname{pd} \sigma$ $\beta)^{1}\left(\mathrm{pd} \pi_{\mathrm{z}} \alpha\right)^{1}\left(\mathrm{pd} \pi_{\mathrm{z}} \beta\right)^{1}\left(\mathrm{pd} \pi_{\mathrm{x}} \alpha\right)^{1}\left(\mathrm{pd} \pi_{\mathrm{x}} \beta\right)^{1}\left(\mathrm{dp} \pi^{*}{ }_{\mathrm{x}} \alpha\right)^{1}\left(\mathrm{dp} \pi_{\mathrm{z}} \alpha\right)^{1}\left(\mathrm{dz}{ }^{2} \alpha\right)^{0}(\mathrm{dxz} \alpha)^{1}$, where both the pd $(\pi$ bonding) orbitals are occupied and the $\delta$ nonbonding is empty, leading to a Mn-O bond order of 2 and getting stabilized by $31.2 \mathrm{kcal} / \mathrm{mol}$ (Figure 8 ). In the sextet spin state the lowest-lying vacant orbital is $\mathrm{pd} \pi_{\mathrm{x}} \beta$, which is bonding between the Mn dxy and $\mathrm{O} \mathrm{p}_{\mathrm{x}}$ orbitals, whereas in the quartet state the lowest-lying vacant orbital is $d p \pi^{*}{ }_{x} \beta$, which is antibonding between the Mn $d x y$ and $O p_{x}$ orbitals (see Figure 9). The energy of the lowest vacant orbital and its oxygen p orbital contribution are the two important factors in predicting the electrophilicity of a $\mathrm{MO}^{2+}$ moiety. Generally speaking, the lower the acceptor orbital lies in energy and the higher the \% oxygen p orbital contribution is, the more electrophilic the $\mathrm{MO}^{2+}$ will be: in our case they are both in favor of a large electronic donation from the $\mathrm{H}-\mathrm{OOH}$ bond into the $\mathrm{MnO}^{2+}$ acceptor orbital. Based on these two factors, a much higher reactivity of the Mn oxo intermediate in the sextet spin state is expected, since both the energy of the acceptor $\mathrm{pd} \pi_{\mathrm{x}} \beta$ orbital is lower $\left(-6.65 \mathrm{eV}\right.$ vs. $-4.19 \mathrm{eV}$ for $\mathrm{dp} \pi^{*}{ }_{\mathrm{x}} \beta$ in the quartet state) and the $\%$ oxygen $p_{\mathrm{x}}$ orbital contribution is higher $\left(59 \% \mathrm{vs} .15 \%\right.$ for $\mathrm{dp} \pi^{*}{ }_{\mathrm{x}} \beta$ in the 
quartet state). The spin density distribution resulting from electronic structure in $\mathrm{PC}_{\mathrm{oxoI}}$ intermediates is shown in Figure $8 . \mathrm{In} \mathrm{PC}_{\mathrm{oxos}}$ the spin density on the metal/ligand system is overall close to four, with roughly three unpaired electrons on the single metal, assigned to high-spin $\mathrm{Mn}(\mathrm{IV})$, and with the fifth unpaired electron localized on the oxo oxygen, leading to an overall electronic structure in the sextet state. $\mathrm{In}_{\mathrm{PC}_{\text {oxoq }}}$ the spin density is 0.64 on the oxo oxygen and close to two on Mn which sums up to three unpaired electrons on the whole complex. Finally, in $\mathrm{PC}_{\text {oxod }}$ one unpaired electron is delocalized over the Mn center and the oxo oxygen. In Table S1 in the SI the Multiple Derived Charges (MDC) spin densities ${ }^{56}$ are reported for all the species (initial complexes (IC), reactant complexes $\left(\mathrm{RC}_{\mathrm{I}}\right)$, intermediates $\left(\mathrm{I}_{\mathrm{OHOH}}, \mathrm{I}_{\mathrm{OH}}\right)$ and product complexes $\left.\left(\mathrm{PC}_{\mathrm{Ioxo}}\right)\right)$ involved in the first dismutation reaction.

In conclusion, the $\left[\mathrm{MnS}_{2} \mathrm{Py}_{3}\right]^{2+}$-catalyzed first dismutation reaction can be described as a multichannel process combining both ping-pong and dihydroxo pathways. The competing channels have different spin states: the sextet reaction pathway corresponds to a ping-pong mechanism, the doublet should allow both a ping-pong and a dihydroxo mechanism, and the quartet would preferably follow a dihydroxo mechanism. Importantly, the two mechanistic channels are characterized by different coordination geometries of the involved species: octahedral in the pingpong route, trigonal prismatic in the dihydroxo path, suggesting that the reaction mechanism is controlled by spin transitions triggered by Mn coordination switching and vice versa. Both the Mn oxo (sextet and quartet spin state) and the Mn dihydroxo (quartet spin state) species have spin density on oxygen, a factor that has been found to be crucial in promoting hydrogen abstraction. ${ }^{79}$ 


\section{Second dismutation reaction}

A manganese(IV) dihydroxo compound in a quartet spin state has been obtained as a thermodynamically stable product from the first dismutation reaction. The second dismutation reaction should convert hydrogen peroxide to two water molecules and dioxygen. The second dismutation reaction has been studied for the quartet and doublet spin states according to this mechanism. However, if the catalyst does not enter the dihydroxo route, namely if the monohydroxo immediately converts into the oxo intermediate, then the ping-pong channel should also be viable for the quartet spin state. Since the ping-pong mechanism is preferred for the sextet spin state, we start in the second dismutation reaction from the oxo intermediate which should convert hydrogen peroxide to one water molecule and dioxygen. Finally, we note that for the doublet spin state, the ping-pong mechanism is also feasible and, since the oxo intermediate is kinetically accessible and thermodynamically more stable than the dihydroxo intermediate, we will consider this as an alternative reactant complex for the second dismutation reaction. Summarizing, on the basis of our findings, two possible mechanistic channels are considered, as shown in Scheme 2: firstly, the ping-pong channel (for the sextet, quartet and doublet spin states) which, starting from $\mathrm{PC}_{\text {oxo }} \mathrm{s}, \mathrm{PC}_{\text {oxo }} \mathrm{q}$ and $\mathrm{PC}_{\text {oxo }} \mathrm{d}$, leads to the conversion of $\mathrm{H}_{2} \mathrm{O}_{2}$ into $\mathrm{H}_{2} \mathrm{O}$ and $\mathrm{O}_{2}$ with simultaneous deoxygenation of the Mn complex; secondly, the dihydroxo channel (for the quartet and the doublet spin states) which, starting from $\mathrm{I}_{\mathrm{OHOH}} \mathrm{q}$ and $\mathrm{I}_{\mathrm{OHOH}} \mathrm{d}$, converts $\mathrm{H}_{2} \mathrm{O}_{2}$ into two $\mathrm{H}_{2} \mathrm{O}$ molecules and $\mathrm{O}_{2}$ with simultaneous dehydroxylation of the metal complex. In the latter case, a hydroxo-hydroperoxo intermediate retaining the trigonal prismatic coordination should be involved. ${ }^{72}$ In the ping-pong channel, the water molecule formed as a product of the first dismutation reaction is included in the energy profile calculations for a direct comparison with the dihydroxo channel energy profile. 


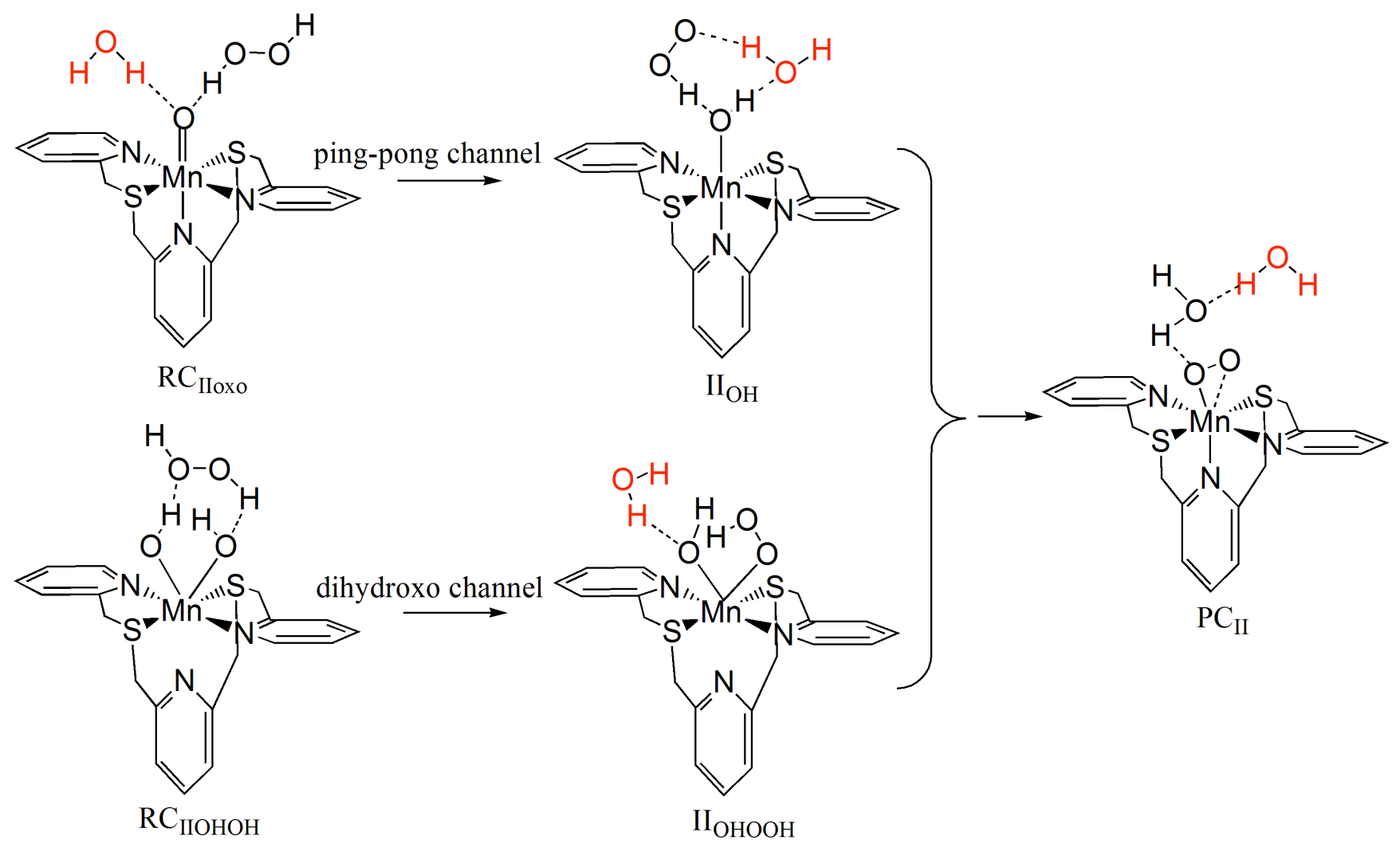

Scheme 2. Reactant complexes, intermediates and the common product complex from the pingpong (top) and dihydroxo (bottom) mechanisms for the second dismutation reaction of hydrogen peroxide catalyzed by $\left[\mathrm{MnS}_{2} \mathrm{Py}_{3}(\mathrm{OH})_{2}\right]^{2+} /\left[\mathrm{MnS}_{2} \mathrm{Py}_{3} \mathrm{O}\right]^{2+}\left(\mathrm{H}_{2} \mathrm{O}\right)$; ping-pong channel: $\mathrm{RC}_{\text {IIoxo }}$ represents the reactant complex from the oxo intermediate $\left(\mathrm{PC}_{\mathrm{Ioxo}}\right)$ and $\mathrm{II}_{\mathrm{OH}}$ the $\mathrm{Mn}$ monohydroxo intermediate (plus a free hydroperoxide moiety); dihydroxo channel: $\mathrm{RC}_{\mathrm{IIOHOH}}$ represents the reactant complex from $\mathrm{I}_{\mathrm{OHOH}}$ intermediate, and $\mathrm{II}_{\mathrm{OHOOH}}$ the $\mathrm{Mn}$ hydroxo-hydroperoxo intermediate. $\mathrm{PC}_{\mathrm{II}}$ represents the same final product complex, which represents the $\mathrm{Mn}(\mathrm{II})$ initial catalyst with a coordinated $\mathrm{O}_{2}$ product molecule plus two product water molecules.

Due to the complex picture of the second dismutation reaction as a multichannel process with different spin states, we present our findings for each spin state separately.

All of the reaction profiles for the three different spin states and for the two pathways (ping-pong 
and dihydroxo) are compared in Figure 10, where the energy of the separate reactants $\mathrm{I}_{\mathrm{OHOH}} \mathrm{q}+$ $\mathrm{H}_{2} \mathrm{O}_{2}$ and $\mathrm{PC}_{\text {oxo }} \mathrm{q}+\mathrm{H}_{2} \mathrm{O}_{2}$ are taken as zero reference energy.

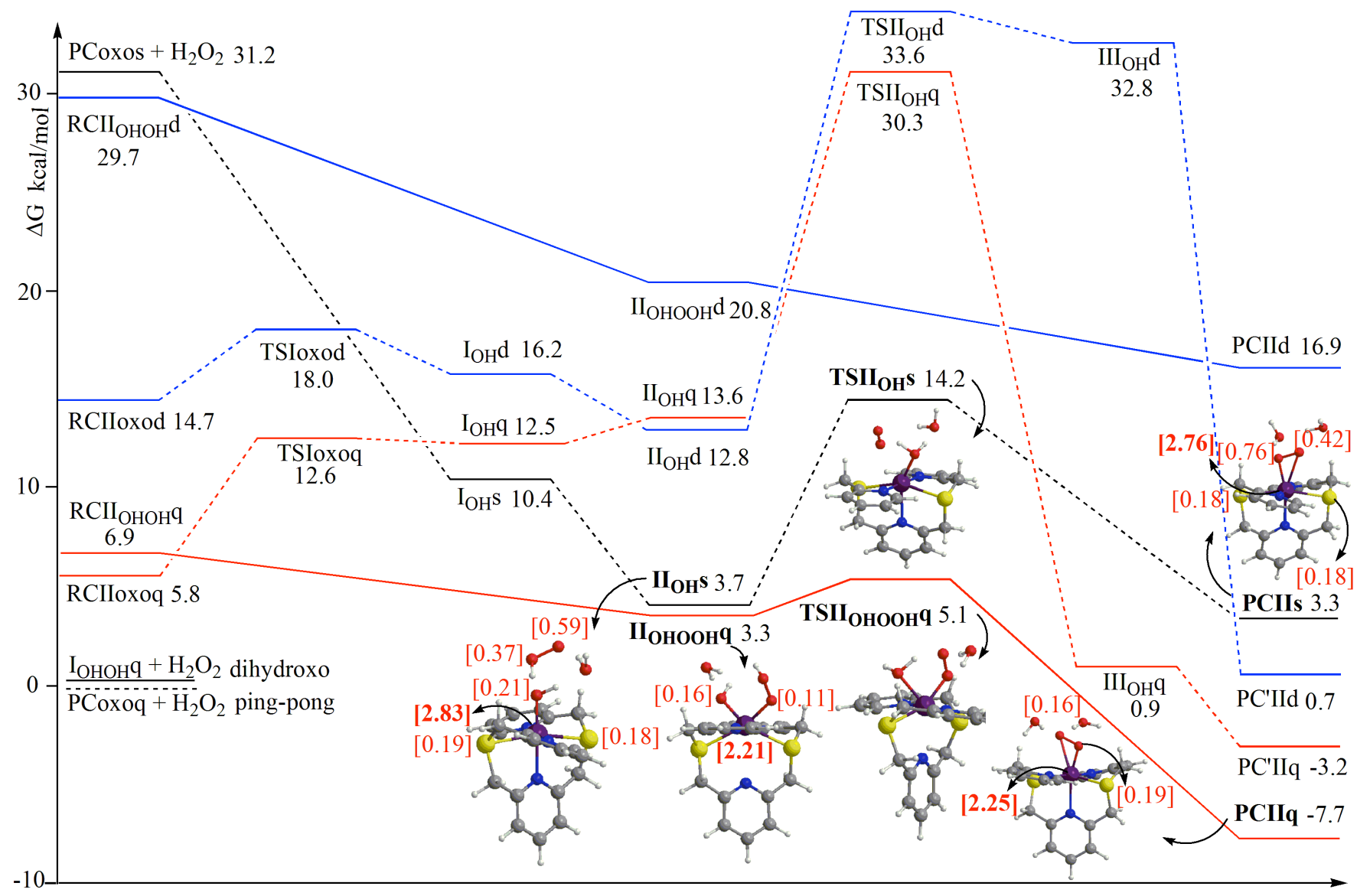


Figure 10. Energy profiles for the second dismutation reaction on the sextet (black), quartet (red) and doublet (blue) spin states. Dashed lines are used for ping-pong pathways, solid lines for dihydroxo pathways. The sum of the Gibbs free energies of the separate reactants $\left(\mathrm{I}_{\mathrm{OHOH}} \mathrm{q}+\mathrm{H}_{2} \mathrm{O}_{2}\right.$ and $\mathrm{PC}_{\mathrm{oxo}} \mathrm{q}+\mathrm{H}_{2} \mathrm{O}_{2}$ ) are taken as zero reference energy. Geometrical structures and spin density on $\mathrm{Mn}, \mathrm{S}$ and $\mathrm{O}$ atoms (values in square brackets, based on Multiple Derived Charges (MDC-q) analysis) of the most relevant species are also shown.

Two very interesting features can be observed from Figure 10: firstly, the strong hydrogenabstraction ability of $\mathrm{PC}_{\mathrm{oxo}} \mathrm{S}$ is responsible for the sextet energy profile to be the lowest energy path for the ping-pong route. A second spin transition from quartet to sextet occurs after the TSIoxoq has been reached with an activation energy barrier of $6.8 \mathrm{kcal} / \mathrm{mol}$ for the first hydrogen abstraction from $\mathrm{H}_{2} \mathrm{O}_{2}$. Secondly, the high reactivity of $\mathrm{I}_{\mathrm{OHOHq}}$ results in a very low barrier along the quartet energy profile for the dihydroxo route. These two features make the ping-pong path on the sextet spin state and the dihydroxo path on the quartet spin state the two minimum energy channels. The rate determining step of the second dismutation reaction is the second hydrogen abstraction from $\mathrm{H}_{2} \mathrm{O}_{2}$, namely by TSII $\mathrm{OHOH}_{\mathrm{q}}$ and $\mathrm{TSII}_{\mathrm{OH}} \mathrm{S}$ in Figure 10 . However, the activation energy barrier along the quartet energy profile is much lower than that along the sextet $(1.8 \mathrm{vs} .10 .5 \mathrm{kcal} / \mathrm{mol}$, respectively).

\section{Sextet state reaction pathway.}

As mentioned above, only the ping-pong mechanism has been considered for the sextet state and a stepwise path has been calculated as depicted in Figure 10 (black dashed line energy profile). The optimized geometries for the involved species can be found in Figure S9 in the SI. Despite many attempts, we failed to find a stable reactant complex $\mathrm{RCII}_{\mathrm{oxo}} \mathrm{s}$ starting from $\mathrm{PC}_{\mathrm{oxo}} \mathrm{S}$ and a vicinal 
$\mathrm{H}_{2} \mathrm{O}_{2}$. The two reactants immediately form the intermediate species $\mathrm{I}_{\mathrm{OH}} \mathrm{S}$ (see Figures 10 and S9) which is stabilized by $20.8 \mathrm{kcal} / \mathrm{mol}$ with respect to the sum of the energies of the separate reactants $\mathrm{PC}_{\text {oxo }} \mathrm{S}+\mathrm{H}_{2} \mathrm{O}_{2}$, thus confirming the strong hydrogen abstraction ability of the Mn(IV)oxo moiety. Intermediate $\mathrm{I}_{\mathrm{OH}} \mathrm{S}$ can be described as a monohydroxo Mn complex with a hydroperoxo group hydrogen-bonded to $\mathrm{Mn}-\mathrm{OH}$ as a hydrogen-acceptor species, with a $\mathrm{OH}-\mathrm{OOH}$ distance of $1.741 \AA$. However, many hydrogen-bonded configurations can be calculated for $\mathrm{H}_{2} \mathrm{O}, \mathrm{OOH}$ and $\mathrm{OH}$ in this species, and among them, the structure denoted $\mathrm{II}_{\mathrm{OH}} \mathrm{S}$ in Figures 10 and $\mathrm{S} 9$ is more stable than $\mathrm{I}_{\mathrm{OH}} \mathrm{S}$ by $6.7 \mathrm{kcal} / \mathrm{mol}$. Importantly, $\mathrm{II}_{\mathrm{OH}} \mathrm{S}$ shows the hydroperoxo group hydrogen-bonded to $\mathrm{Mn}-\mathrm{OH}$ as the hydrogen-donor species, with a $\mathrm{OOH}-\mathrm{OH}$ distance of $1.406 \AA$. Note that the $\mathrm{OOH}$ peroxide position in $\mathrm{II}_{\mathrm{OH}} \mathrm{S}$ is a suitable starting point for the second proton transfer. In the $\mathrm{OOH}$ hydrogen approach to $\mathrm{OH}-\mathrm{Mn}$, the energy goes uniformly uphill and neither a transition state nor a product complex with a water molecule bound to Mn could be found, thus signaling the weak hydrogen abstraction ability of the Mn-OH complex. Instead a transition state for the second proton transfer can be reached by rotating the peroxide moiety to allow an oxygen atom interaction with Mn. The $\mathrm{TSII}_{\mathrm{OH}} \mathrm{S}$ geometry, depicted in Figure $\mathrm{S}$, is characterized by an almost completely abstracted hydrogen $(\mathrm{OO}-\mathrm{H}$ distance $=1.554 \AA$, OOH-OH distance $=1.045 \AA)$, a shortening of the $\mathrm{O}-\mathrm{OH}$ bond (1.336 $\AA$ ) and an early stage formation of the OO-Mn bond with a distance between O and Mn of $2.557 \AA$. The $\mathrm{TSII}_{\mathrm{OH}} \mathrm{S}$ structure leads directly to the product complex $\mathrm{PC}_{\mathrm{II}} \mathrm{S}$ (Figures 10 and S9). In the final complex the dioxygen molecule is coordinated to the Mn center approximately in an end-on mode $(\mathrm{Mn}-\mathrm{O} 1=1.937 \AA, \mathrm{Mn}-\mathrm{O} 2=2.449 \AA, \mathrm{O} 1-\mathrm{O} 2=1.334 \AA)$. The energy barrier corresponding to $\mathrm{TSII}_{\mathrm{OH}} \mathrm{S}$ is $10.5 \mathrm{kcal} / \mathrm{mol}$ and the reaction is endothermic by $3.3 \mathrm{kcal} / \mathrm{mol}$ with respect to separate reactants $\mathrm{PC}_{\text {oxo }} \mathrm{q}+\mathrm{H}_{2} \mathrm{O}_{2}$ and exothermic by $27.9 \mathrm{kcal} / \mathrm{mol}$ with respect to separate $\mathrm{PC}_{\mathrm{oxo}} \mathrm{S}+\mathrm{H}_{2} \mathrm{O}_{2}$.

The electronic structure analysis of $\mathrm{II}_{\mathrm{OH}} \mathrm{S}$ shows that the lowest $\alpha$-spin vacant orbital can be described as a $\sigma^{*}$ orbital between the oxygen atom of the $\mathrm{OH}\left(8 \% \mathrm{p}_{\mathrm{y}}\right)$ and $\mathrm{Mn}\left(27 \% \mathrm{dxy}+20 \mathrm{dx}^{2}-\right.$ $\mathrm{y}^{2}$ ) which is a suitable acceptor orbital in the hydrogen abstraction reactivity. Both its relatively high 
energy $\left(-4.623 \mathrm{eV}\right.$ with respect to $-5.268 \mathrm{eV}$ of the lowest $\beta$-spin vacant orbital of $\mathrm{OOH} \pi^{*}$ character) and low oxygen $\mathrm{p}$ orbital contribution $(8 \%)$ are responsible for the calculated 10.5 $\mathrm{kcal} / \mathrm{mol}$ energy barrier. The spin density distribution resulting from its electronic structure is shown in Figure 10. The $\mathrm{II}_{\mathrm{OH}} \mathrm{s}$ has four unpaired electrons on the metal complex (roughly three on Mn and one delocalized over the $\mathrm{S}$ donor atoms and $\mathrm{OH}$ oxygen atom), and one unpaired electron on $\mathrm{OOH}$ moiety, the latter showing a radical character, which leads the overall species to a sextet spin state. In conclusion, in the sextet reaction channel a ping-pong mechanism would be feasible, with the second proton transfer being the rate-determining step of the second dismutation reaction.

\section{Quartet state reaction pathway.}

It was found that the reaction in the quartet spin state could proceed through a dihydroxo mechanism. When the second $\mathrm{H}_{2} \mathrm{O}_{2}$ substrate approaches the dihydroxo intermediate $\mathrm{I}_{\mathrm{OHOH}} \mathrm{q}$, two possible conformations for the reactant complex $\mathrm{RCII}_{\mathrm{OHOH}}$ can be obtained, based on the two hydrogen bonds which can be formed between the hydrogen atoms of $\mathrm{H}_{2} \mathrm{O}_{2}$ and the two $\mathrm{OH}$ groups coordinated to $\mathrm{Mn}$. In the first configuration, denoted as $\mathrm{RCII} \mathrm{OHOH}_{\mathrm{q}}, \mathrm{H}_{2} \mathrm{O}_{2}$ acts as a proton donor for one bond and as a proton acceptor for the other. In the second configuration, denoted as RC' $\mathrm{II}_{\mathrm{OHOH}} \mathrm{q}, \mathrm{H}_{2} \mathrm{O}_{2}$ acts as proton donor for both bonds. The optimized geometries of the two reactant complexes are depicted in Figure S10 in the SI. The most stable reactant complex is $\mathrm{RCII}_{\mathrm{OHOH}} \mathrm{q}$, which is less stable than the sum of the Gibbs free energies of the isolated reactants $\left(\mathrm{I}_{\mathrm{OHOH}} \mathrm{q}+\mathrm{H}_{2} \mathrm{O}_{2}\right)$ by $6.9 \mathrm{kcal} / \mathrm{mol}$. The alternative reactant complex in the quartet spin state, RC' $\mathrm{II}_{\mathrm{OHOH}} \mathrm{q}$, is $12.0 \mathrm{kcal} / \mathrm{mol}$ higher in energy than the free reactants. In the $\mathrm{RCII}_{\mathrm{OHOH}} \mathrm{q}$ structure an incipient hydrogen abstraction from $\mathrm{H}_{2} \mathrm{O}_{2}$ is observed $\left(\mathrm{H}_{2} \mathrm{O}_{2} \mathrm{O}-\mathrm{H}=1.015 \AA\right)$, and a simultaneous elongation of the hydrogen abstracting $\mathrm{HO}-\mathrm{Mn}$ bond (1.872 $\AA$ ). From $\mathrm{RCII}_{\mathrm{OHOH}}$, through a barrierless reaction (red solid line energy profile in Figure 10), a Mn(IV) hydroxo hydroperoxo intermediate complex is formed ( $\mathrm{II}_{\mathrm{OHOOHq}}$ in Figure 10 and $\left.\mathrm{S} 10\right)$ which is more stable than 
$\mathrm{RCII}_{\mathrm{OHOH}} \mathrm{q}$ by $3.6 \mathrm{kcal} / \mathrm{mol}$. A water molecule is released with the hydroperoxo group substituting the leaving $\mathrm{H}_{2} \mathrm{O}$ ligand in the $\mathrm{Mn}$ coordination sphere. Note that the $\mathrm{Mn}$ coordination features in $\mathrm{I}_{\mathrm{OHоOн}} \mathrm{q}$ (in particular the elongated $\mathrm{Mn}-\mathrm{N}$ pyridine bond trans to the two hydroxo ligands leading to the trigonal prismatic coordination geometry in $\mathrm{I}_{\mathrm{OHOH}} \mathrm{q}$ ) are retained (see Figure $\mathrm{S} 10$ ). Starting from the geometry of $\mathrm{I}_{\mathrm{OHOон}} \mathrm{q}$, the $\mathrm{TSII}_{\mathrm{OHOOH}} \mathrm{q}$ structure can be obtained by forcing the $\mathrm{H}$ atom of the hydroperoxide ligand towards the oxygen of the hydroxide ligand. In the $\mathrm{TSII}_{\mathrm{OHOOH}} \mathrm{q}$ geometry (see Figure S10), the hydrogen has been largely transferred to $\mathrm{OH}(\mathrm{OO}-\mathrm{H}$ distance $=1.437 \AA$, HO$\mathrm{H}$ distance $=1.070 \AA$ ), with a simultaneous shortening of the $\mathrm{O}-\mathrm{O}$ distance in the hydroperoxide moiety $\left(1.384 \AA\right.$ ). The $\mathrm{TSII}_{\mathrm{OHоOн}} \mathrm{q}$ transition state leads to the product complex PCIIq (see Figures 10 and S10) which consists of a dioxygen molecule coordinated to Mn in a end-on fashion (Mn-O1 $=1.815 \AA, \mathrm{Mn}-\mathrm{O} 2=2.418 \AA, \mathrm{O} 1-\mathrm{O} 2=1.395 \AA$ ) and two water molecules hydrogen-bonded to $\mathrm{O}_{2}$. A very modest amount of energy $(1.8 \mathrm{kcal} / \mathrm{mol})$ is needed to activate this step. The PCIIq product complex is more stable than $\mathrm{RCII}_{\mathrm{OHOH}} \mathrm{q}$ by $14.6 \mathrm{kcal} / \mathrm{mol}$ and it is also more stable than PCIIs by $11.0 \mathrm{kcal} / \mathrm{mol}$. Our study reveals that the intermediate $\mathrm{I}_{\mathrm{OHон}} \mathrm{q}$ formed in the first dismutation reaction rapidly evolves to give two $\mathrm{H}_{2} \mathrm{O}$ and one $\mathrm{O}_{2}$ product molecules, with a very low energy cost (dihydroxo mechanism). The lowest $\alpha$-spin vacant orbital of $\mathrm{II}_{\mathrm{OHоон}} \mathrm{q}$ has a mainly metal character $\left(13 \% d x y+16 d^{2}-y^{2}+9 \% d z^{2}+8 \% d x z\right)$ with a small contribution from the oxygen atom of $\mathrm{OH}\left(4 \% \mathrm{p}_{\mathrm{z}}+2 \% \mathrm{p}_{\mathrm{y}}\right)$, interacting in an antibonding fashion. This orbital can be a suitable acceptor orbital in the hydrogen abstraction, with a relatively low energy $(-5.284 \mathrm{eV})$, although the oxygen p orbital contribution $(6 \%)$ is also low. The $\mathrm{II}_{\mathrm{OHоOн}} \mathrm{q}$ has somewhat more than two unpaired electrons on the metal complex, roughly two on $\mathrm{Mn}$ and the remaining delocalized over the $\mathrm{OH}$ (0.16) and $\mathrm{OOH}(0.11)$ oxygen atoms (see Figure 10).

However, as mentioned above, one may argue that the catalyst could be temporarily deactivated for the ping-pong mechanism if it entered the dihydroxo reaction route in the first dismutation process, due to formation of the thermodynamically stable $\mathrm{I}_{\mathrm{OHOH}} \mathrm{q}$. The issue we want to address now is what 
happens if the catalyst does not enter the $\mathrm{I}_{\mathrm{OHOH}} \mathrm{q}$ reaction path but it follows the ping-pong mechanism.

The energy profile for this stepwise path is depicted in Figure 10 as dashed red lines. The optimized geometries of the involved species can be found in Figure S11 in the SI.

The reaction starts with the reactant complex RCIIoxoq which is less stable than the separate reactants $\mathrm{PC}_{\text {oxo }} \mathrm{q}+\mathrm{H}_{2} \mathrm{O}_{2}$ by $5.8 \mathrm{kcal} / \mathrm{mol}$. The hydrogen abstraction by the Mn-oxo requires an activation energy barrier of $6.8 \mathrm{kcal} / \mathrm{mol}$ through a transition state characterized by a very productlike structure (TSIoxoq), leading to intermediate $\mathrm{I}_{\mathrm{OHq}}$ in Figure 10 and S11. Geometry rearrangement to yield the structure denoted $\mathrm{II}_{\mathrm{OH}} \mathrm{q}$ further destabilizes $\mathrm{I}_{\mathrm{OH}} \mathrm{q}$ by $1.1 \mathrm{kcal} / \mathrm{mol}$, and, as for the sextet, it shows the hydroperoxo group hydrogen-bonded to $\mathrm{Mn}-\mathrm{OH}$ acting as a hydrogendonor, with a OOH-OH distance of $1.418 \AA$. Analogously to the sextet spin route, in the $\mathrm{OOH}$ hydrogen approach to $\mathrm{OH}-\mathrm{Mn}$, the energy goes uniformly uphill and neither a transition state nor a product complex with a water molecule bound to Mn could be calculated, but, rather, a transition state for the second proton transfer can be reached by allowing an oxygen atom of $\mathrm{OOH}$ to interact with $\mathrm{Mn}$. The $\mathrm{TSII}_{\mathrm{OH}} \mathrm{q}$ geometry is depicted in Figure $\mathrm{S} 11$ and it is characterized by a very early stage hydrogen abstraction $(\mathrm{OO}-\mathrm{H}$ distance $=0.997 \AA, \mathrm{OOH}-\mathrm{OH}$ distance $=2.075 \AA$ ), a lengthening of the $\mathrm{O}-\mathrm{OH}$ bond $(1.463 \AA)$ and an early stage formation of the OO-Mn bond with a distance between $\mathrm{O}$ and $\mathrm{Mn}$ of $2.317 \AA$. The $\mathrm{TSII}_{\mathrm{OH}} \mathrm{q}$ structure leads to intermediate $\mathrm{III}_{\mathrm{OH}} \mathrm{q}$ with an energy barrier of $16.7 \mathrm{kcal} / \mathrm{mol}$ and this step is exothermic by $12.7 \mathrm{kcal} / \mathrm{mol}$. III $_{\mathrm{OH}} \mathrm{q}$ structure is characterized by a significant geometrical rearrangement with respect to $\mathrm{TSII}_{\mathrm{OH}}$, most noticeable the de-coordination of one of the equatorial pyridyl ligands $(\mathrm{Mn}-\mathrm{N}=3.890 \AA)$. The hydrogen transfer from $\mathrm{OOH}$ to $\mathrm{OH}$ leads to the product complex $\mathrm{PC}^{\prime} \mathrm{IIq}$, whose structure is very different from that of PCIIq (see Figure S10). In PC'IIq the dioxygen molecule is coordinated in a side-on mode $(\mathrm{Mn}-\mathrm{O} 1=1.820 \AA, \mathrm{Mn}-\mathrm{O} 2=1.808 \AA, \mathrm{O} 1-\mathrm{O} 2=1.439 \AA)$, showing the formation of a $\mathrm{O}_{2}-$ Mn adduct. Overall, the quartet channel seems to be viable in the second dismutation reaction only for the dihydroxo mechanism. To demonstrate that PCIIq represents the initial sextet catalyst plus a 
triplet $\mathrm{O}_{2}$ molecule anti-ferromagnetically coupled, the corresponding structure in the octet spin state, PCIIo, where the initial catalyst and $\mathrm{O}_{2}$ are ferromagnetically coupled, has been optimized. The geometry is shown in Figure S14 in the SI, where the alternative product complex with a $\mathrm{H}_{2} \mathrm{O}$ molecule coordinated to $\mathrm{Mn}$ (PC'IIo) has also been calculated. Incidentally, PC'IIo, with the $\mathrm{O}_{2}$ molecule in the second coordination sphere and thus without magnetic coupling, is more stable than PCIIo by $9.9 \mathrm{kcal} / \mathrm{mol}$. On comparing the PCIIo geometry with that of the initial catalyst shown in Figure 1 (middle), we can see that they are very similar. The high spin of PCIIo is however less stable than the anti-ferromagnetically coupled PCIIq by $1.4 \mathrm{kcal} / \mathrm{mol}$. A single point broken symmetry calculation using the geometry of PCIIo with spin- $\alpha$ density on the metal (five $\alpha$ spin unpaired electrons) and spin- $\beta$ density on $\mathrm{O}_{2}$ (two $\beta$ spin unpaired electrons), resulting in a quartet spin state ("low spin"), has been carried out. The high spin octet configuration is computed to be less stable than the "low spin" broken symmetry configuration by $1.5 \mathrm{kcal} / \mathrm{mol}$, thus showing that PCIIq indeed represents the initial catalyst plus a triplet $\mathrm{O}_{2}$ molecule anti-ferromagnetically coupled. The spin density distribution in PCIIq, showing roughly three unpaired electrons on the metal and small spin density on $\mathrm{O}_{2}(0.19$ and 0.16$)$, indeed supports an anti-ferromagnetically coupled spin between $\mathrm{O}_{2}$ (two unpaired electrons) and the sextet $\mathrm{Mn}$ (II) (five unpaired electrons). Finally, we briefly comment on the lack of reactivity in the hydrogen abstraction for $\mathrm{II}_{\mathrm{OH}} \mathrm{q}$ species in Figure 10. Inspection of its electronic structure reveals that the lowest lying vacant orbital has mainly $\mathrm{OOH}$ character, and no suitable acceptor orbitals containing $\mathrm{OH}$ contribution are available at low energies.

For the doublet state reaction pathway, we note that the doublet spin state has shown intermediate features between those of the quartet and the sextet reactions. The second dismutation process in the doublet state can in principle proceed via both a ping-pong and a dihydroxo mechanism, since both $\mathrm{PC}_{\text {oxo }} \mathrm{d}$ and $\mathrm{I}_{\mathrm{OHOH}} \mathrm{d}$ are accessible species. However, the energy profiles for both mechanisms are always higher than those for the sextet and quartet spin states, therefore the doublet state reaction pathway seems unfavorable in the second dismutation reaction for both channels. Results for the 
second dismutation reaction in the doublet spin state are discussed in detail in the SI (Figures S12 and S13 ).

Spin density values for all the species involved in the second dismutation reaction can be found in the SI (Tables S2-S5).

Summarizing: the overall $2 \mathrm{H}_{2} \mathrm{O}_{2} \rightarrow 2 \mathrm{H}_{2} \mathrm{O}+\mathrm{O}_{2}$ dismutation reaction catalyzed by $\left[\mathrm{MnS}_{2} \mathrm{Py}_{3}\right]^{2+}$ can occur through two competing channels: the ping-pong mechanism along the sextet and the dihydroxo mechanism along the quartet pathway. Both share the same rate determining step (RDS) in the first dismutation reaction: the $\mathrm{O}-\mathrm{O}$ bond breaking of $\mathrm{H}_{2} \mathrm{O}_{2}$ which occurs in the sextet spin state with an activation barrier of $9.0 \mathrm{kcal} / \mathrm{mol}$. In the next subsection we will further explore the RDS to elucidate the role of the explicit solvent, counterion and water (trace amounts) on this activation energy barrier for the first dismutation reaction.

\section{Solvent, counterion and water effects on the $\mathrm{O}-\mathrm{O}$ bond breaking of $\mathrm{H}_{2} \mathrm{O}_{2}$}

The role of solvent, counterion and trace amount of water in acetonitrile can be important in the $\mathrm{H}_{2} \mathrm{O}_{2}$ bond breaking process on the sextet spin state in the first dismutation reaction. For this reason we also considered the $\mathrm{O}-\mathrm{O}$ bond cleavage in the presence of explicit solvent (two acetonitrile molecules), the anion (OTf) and traces of water (four $\mathrm{H}_{2} \mathrm{O}$ molecules) together with the COSMO

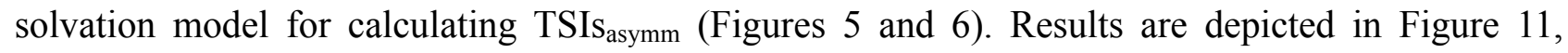
where energy profiles for the $\mathrm{O}-\mathrm{O}$ bond breaking of $\mathrm{H}_{2} \mathrm{O}_{2}$ in the presence of two acetonitrile molecules, OTf and four water molecules are compared to that shown in Figure 5 taken as reference (only COSMO). 


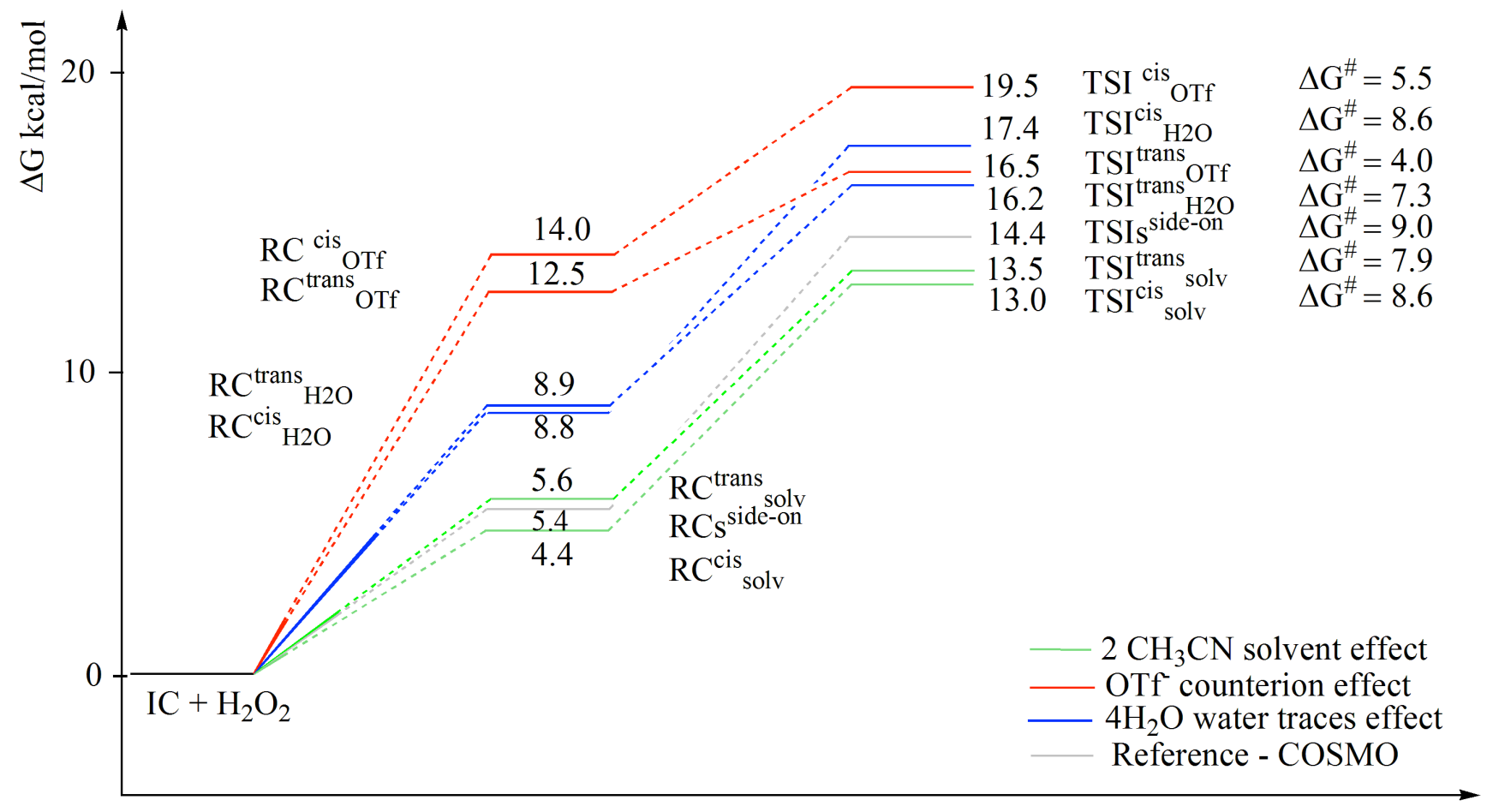

Figure 11. Energy profiles for the $\mathrm{O}-\mathrm{O}$ bond breaking of $\mathrm{H}_{2} \mathrm{O}_{2}$ in the first dismutation reaction for the sextet spin state. Green lines are for the presence of two explicit acetonitrile molecules, red lines for the inclusion of OTf, blue lines for the presence of four water molecules, and the grey line for solvent included only by the implicit COSMO model (Figure 5). $\mathrm{RC}^{\mathrm{cis}}$ and $\mathrm{TS}^{\mathrm{cis}}$ denote reactant complexes and transition states with the same ligand coordination mode (mmf) as in $\mathrm{RCs}^{\text {end-on }}$ in Figure 3; $\mathrm{RC}^{\text {trans }}$ and $\mathrm{TS}^{\text {trans }}$ represent reactant complexes and transition states with the same ligand coordination mode ( $\mathrm{fmf}$ ) as in $\mathrm{RCs}^{\text {side-on }}$ in Figure 3. The sum of the Gibbs free energies of the separate reactants ( $\mathrm{IC}+\mathrm{H}_{2} \mathrm{O}_{2}$ ) (see corresponding ICs in Figure $\mathrm{S} 15$ in the $\mathrm{SI}$ ) is taken as zero reference energy. $\Delta \mathrm{G}^{\#}$ values represent the free energy barriers with respect to the reactant complex.

In each case we calculated the corresponding initial complex $\mathrm{IC}_{\text {solv }}, \mathrm{IC}_{\mathrm{OTf}}$ and $\mathrm{IC}_{\mathrm{H} 2 \mathrm{O}}$, respectively 
(geometries are shown in Figure S15 in the SI) and the Gibbs free energies of the separate reactants $\mathrm{IC}+\mathrm{H}_{2} \mathrm{O}_{2}$ are taken as zero reference energy. We should recall here that in the reactant complex in the sextet spin state two different coordination modes around Mn have been found using only COSMO: in the RCs ${ }^{\text {end-on }}$ mmf structure coordination of $\mathrm{H}_{2} \mathrm{O}_{2}$ occurs in cis position with respect to the central Py ring of the ligand, whereas in the $\mathrm{RCs}^{\text {side-on }}$ fmf structure it takes place trans to it, retaining the initial catalyst coordination mode (see Figure 3). Interestingly, inclusion of additional solvent, triflate or water only leads to $\mathrm{H}_{2} \mathrm{O}_{2}$ binding in an end-on mode to the metal center, both in the $\mathrm{RCs}^{\text {end-on }}$-type and $\mathrm{RCs}{ }^{\text {side-on }}$-type coordination around $\mathrm{Mn}$, in contrast to what was found using only COSMO, where the side-on binding of hydrogen peroxide was even preferred by $4.3 \mathrm{kcal} / \mathrm{mol}$ over the end-on mode. To account for the two different structures, in Figure 11 the species RCs and TSs with $\mathrm{H}_{2} \mathrm{O}_{2}$ coordination in cis position with respect to the central Py ring of the ligand are denoted with superscript cis, whereas species with $\mathrm{H}_{2} \mathrm{O}_{2}$ bonded in trans position with superscript trans. In $\mathrm{RC}^{\text {trans }}$ structures, the two Mn-O bond lengths are 2.252 and $2.895 \AA$ with inclusion of two acetonitrile molecules, 2.283 and $2.698 \AA$ with inclusion of four water molecules and 2.178 and $2.797 \AA$ with inclusion of triflate counterion (see Figure S15 in the SI). This finding suggests that $\mathrm{H}_{2} \mathrm{O}_{2}$ coordinated in the end-on form represents the actual reactive species also in the $\mathrm{RCs}^{\text {side-on }}$ type structure and further corroborates the preference for the asymmetric O-O bond breaking process we found before. Notably, the presence of two explicit acetonitrile molecules significantly stabilizes the $\mathrm{RC}^{\mathrm{cis}}$ solv with respect to the reference COSMO RCs ${ }^{\text {end-on }}$ (by $5.3 \mathrm{kcal} / \mathrm{mol}$, compare $\mathrm{RC}^{\mathrm{cis}}$ solv with $\mathrm{RCs}^{\text {end-on }}$ in Figure 3), whereas it only slightly destabilizes the $\mathrm{RC}^{\text {trans }}{ }_{\text {solv }}$ with respect to $\mathrm{RCs}^{\text {side-on }}$ (by $0.2 \mathrm{kcal} / \mathrm{mol}$, compare $\mathrm{RC}^{\text {trans }}{ }_{\text {solv }}$ with $\mathrm{RCs}^{\text {side-on }}$ in Figure 11). Inclusion of trace amounts of water destabilizes the $\mathrm{RC}^{\text {trans }}{ }_{\mathrm{H} 2 \mathrm{O}}$ with respect to $\mathrm{RCs}^{\text {side-on }}$ by $3.5 \mathrm{kcal} / \mathrm{mol}$, with $\mathrm{RC}^{\text {cis }}$

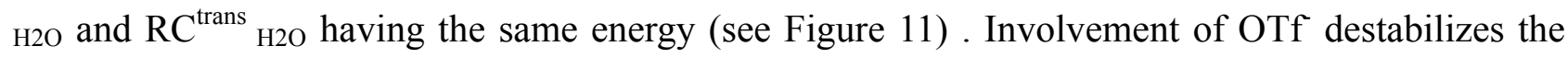
$\mathrm{RC}^{\text {trans }}$ oTf with respect to $\mathrm{RCs}^{\text {side-on }}$ by $7.1 \mathrm{kcal} / \mathrm{mol}$, with $\mathrm{RC}^{\text {trans }}$ otf being preferred over the $\mathrm{RC}^{\mathrm{cis}}$ OTf by $1.5 \mathrm{kcal} / \mathrm{mol}$. Explicit solvent inclusion also slightly stabilizes both transition states $\mathrm{TSI}_{\text {solv }}^{\text {trans }}$ and $\mathrm{TSI}^{\mathrm{cis}}{ }_{\text {solv }}\left(\mathrm{TSIs}^{\text {side-on }} 14.4 \mathrm{kcal} / \mathrm{mol}\right.$ in Figure 11$)$, thus decreasing the free energy barrier with 
respect to the reactant complex $\Delta \mathrm{G}^{\#}$ (7.9 vs. $9.0 \mathrm{kcal} / \mathrm{mol}$ for $\mathrm{TSI}^{\text {trans }}{ }_{\text {solv }}$ and $\mathrm{TSIs}^{\text {side-on }}$, respectively). As a general trend, the $\Delta \mathrm{G}^{\#}$ calculated with $\mathrm{TSI}^{\text {trans }}$-type coordination species are lower than those computed with the TSI ${ }^{\mathrm{cis}}$-type coordination species. The $\Delta \mathrm{G}^{\#}$ is largely decreased in the presence of the counterion $\left(4.0\right.$ and $9.0 \mathrm{kcal} / \mathrm{mol}$ for $\mathrm{TSI}^{\text {trans }}$ OTf and TSIs ${ }^{\text {side-on }}$, respectively), although the transition state energy is increased $(16.5$ vs. $14.4 \mathrm{kcal} / \mathrm{mol})$. Finally, the $\Delta \mathrm{G}^{\#}$ is slightly decreased (7.3 vs. $9.0 \mathrm{kcal} / \mathrm{mol}$ ) and the transition state energy is largely enhanced with inclusion of trace amounts of water $(16.2 \mathrm{vs} .14 .4 \mathrm{kcal} / \mathrm{mol})$. We conclude that the effect of explicit solvent is crucial in determining the actual reactive species in the first dismutation reaction, which is the $\mathrm{H}_{2} \mathrm{O}_{2}$ coordinated in the end-on form. Remarkably, inclusion of explicit solvent also stabilizes the end-on coordination mode of $\mathrm{H}_{2} \mathrm{O}_{2}$ to the metal center in cis position with respect to the central ligand Py ring, which becomes more stable than the $\mathrm{H}_{2} \mathrm{O}_{2}$ coordination trans to it $(4.4 \mathrm{vs} .5 .6 \mathrm{kcal} / \mathrm{mol}$, respectively). In addition, inclusion of explicit solvent affects the activation barrier for the O-O bond breaking, which is slightly decreased ( 7.9 and 8.6 vs. $9.0 \mathrm{kcal} / \mathrm{mol}$, respectively). Both trace amounts of water and OTf increase the reactant complex and the transition state energy with respect to the separate reactants, which will not favor this process. Finally, since we have found that the activation energy barrier for the RDS of the first dismutation reaction is slightly decreased by inclusion of explicit solvent molecules, we expect that insertion of two explicit acetonitrile molecules will influence the activation energy barrier for the RDS of the second dismutation reaction along the sextet pathway. Optimization calculations performed on $\mathrm{II}_{\mathrm{OH}} \mathrm{S}$ and $\mathrm{TSII} \mathrm{OH}_{\mathrm{S}} \mathrm{s}$ are depicted in Figure S16 in the SI. Similarly, $\Delta \mathrm{G}^{\#}$ is found to decrease slightly from $10.5 \mathrm{kcal} / \mathrm{mol}$ (COSMO only) to $9.0 \mathrm{kcal} / \mathrm{mol}$. On the basis of these findings, we can reasonably conclude that O$\mathrm{O}$ bond breaking process in the first dismutation reaction can be considered the RDS for the overall reaction for the dihydroxo pathway, whereas both the $\mathrm{O}-\mathrm{O}$ bond breaking in the first dismutation reaction and the second hydrogen abstraction from $\mathrm{H}_{2} \mathrm{O}_{2}$ in the second dismutation process have very close activation barriers $(7.9$ and $9.0 \mathrm{kcal} / \mathrm{mol}$, respectively) for the ping-pong pathway. Molecular dynamic calculations, which are beyond the scope of this paper, would be useful to 
definitely discriminate the RDS for the overall reaction between these two steps and to elucidate the role of a viable $\mathrm{H}_{2} \mathrm{O}_{2}$ coordination in a cis position with respect to the central Py ring of the ligand in the reactant complex in the first dismutation reaction.

\section{Conclusions}

The present work describes a DFT S12g functional computational study on the mechanism of $\mathrm{H}_{2} \mathrm{O}_{2}$ dismutation reaction catalyzed by the $\left[\mathrm{MnS}_{2} \mathrm{Py}_{3}(\mathrm{OTf})_{2}\right]$ complex that acts as a catalase mimic and for which experimental data are available. ${ }^{23}$ In our calculations the complex has been preventively analyzed in terms of coordination properties since experimental X-ray structural data were lacking. We found that a $\left[\mathrm{MnS}_{2} \mathrm{Py}_{3}\right]^{2+}$ complex in a distorted square pyramidal coordination geometry is the proper catalyst for the reaction with the peroxide molecule. The sextet, quartet and doublet potential energy profiles of the catalytic reaction have been explored.

In the first dismutation reaction the rate-determining step is found to be the asymmetric O-O bond cleavage, which occurs on the sextet potential energy profile. A subsequent spin crossover from sextet to quartet, driven by a geometry coordination change at the metal center, can take place generating a stable $\mathrm{Mn}(\mathrm{IV})$ dihydroxo intermediate which represents a deactivated form of the catalyst in the ping-pong mechanism. However, we have shown that the formation of this stable intermediate paves the way to an alternative reaction pathway for the second dismutation process, termed the dihydroxo mechanism. These two competing channels have different spin states: the sextet reaction pathway corresponds to a ping-pong mechanism, whereas the quartet reaction follows preferably a dihydroxo mechanism where the two water molecules and dioxygen are very easily and simultaneously formed in the second dismutation process. The reaction mechanism is controlled by a spin state crossover triggered by Mn coordination switching from octahedral (in the 
ping-pong route) to trigonal prismatic (in the dihydroxo path). The doublet reaction path is unimportant for both channels since it is always energetically disfavored. Our results suggest that the bottleneck for the whole dismutation process is however the O-O bond breaking step in the first dismutation process for the dihydroxo pathway, whereas both the O-O bond breaking step in the first dismutation process and the second hydrogen abstraction from $\mathrm{H}_{2} \mathrm{O}_{2}$ in the second dismutation process present very close activation barriers for the ping-pong pathway. Explicit solvent, counterion and traces of water inclusion further supports the preference for the asymmetric O-O bond breaking by favoring the $\mathrm{H}_{2} \mathrm{O}_{2}$ end-on coordination mode. This finding can be ascribed to the steric effects exerted by these external species on coordination geometries which, due to the absence of any crystal field stabilization energy for the high-spin $\mathrm{d}^{5} \mathrm{Mn}$ complex, are subjected to a facile intramolecular ligand reorganization process. Inclusion of explicit solvent molecules slightly decreases the activation energy barrier, as well as trace of water and counterion involvement, although in the latter cases as a consequence of the destabilization of the corresponding reactant complexes. In addition, explicit solvent calculations suggest the possibility that an alternative coordination site of the first substrate molecule to the metal, namely a reactant complex with $\mathrm{H}_{2} \mathrm{O}_{2}$ in cis position with respect to the central Py ring of the ligand instead of in trans to it, could also be a reactive species in the dismutation process. Analogously, inclusion of explicit solvent molecules slightly decreases the activation energy barrier for the second hydrogen abstraction from $\mathrm{H}_{2} \mathrm{O}_{2}$ in the second dismutation reaction. The present study on the mechanism of the catalase-like activity of $\left[\mathrm{MnS}_{2} \mathrm{Py}_{3}\right]^{2+}$ complex would benefit from explicit-solvent molecular dynamic simulations, which are however beyond the scope of this paper, that can increase the information to aid in the evaluation of the preferred pathway. It is important to point out that on the basis of our detailed analysis of the mode of action of the $\left[\mathrm{MnS}_{2} \mathrm{Py}_{3}\right]^{2+}$ - catalase mimic we can confirm the experimental evidence that a monomeric $\mathrm{Mn}(\mathrm{IV})$ dihydroxo complex can represent the activated form of the catalyst in some oxidation reactions. Moreover, the current work, disclosing an alternative reaction path for a Mn (II) complex bearing a pentadentate NSNSN ligand, could be helpful for further 
improvement in the structural design of manganese complexes as synthetic catalytic scavengers of hydrogen peroxide of pharmaceutical relevance.

\section{Associated content}

\section{Supporting Information}

Details of the mechanistic computational study, optimized geometries, spin density distribution for all the species and Cartesian coordinates for all the calculated structures.

\section{Author information}

\section{Corresponding Authors:}

*E-mail for M.S.: marcel.swart@icrea.cat

*E-mail for P.B.: paola.belanzoni@unipg.it

\section{Notes}

The authors declare no competing financial interest.

\section{Acknowledgements}

This work has been carried out in the framework of the COST action CM1305 "Explicit Control Over Spin-states in Technology and Biochemistry (ECOSTBio)”.

\section{References:}

1) Gutteridge, J.M.C.; Halliwell, B. Free Radical Biol. Med. 1992, 12, 93-94.

2) Halliwell, B. Lancet 1994, 344, 721-724.

3) Barynin, V.V.; Whittaker, M.M.; Antonyuk, S.V.; Lamzin, V.S.; Harrison, P.M.; Artymiuk, 
P.J.; Whittaker, J.W. Structure 2001, 9, 725-738.

4) Signorella, S.; Hureau, C. Coord. Chem. Rev. 2012, 256, 1229-1245.

5) Wu, A.J.; Penner-Hahn, J.; Pecoraro, V.L. Chem. Rev. 2004, 104, 903-938.

6) Mathur, P.; Crowder, M.; Dismukes, G.C. J. Am. Chem. Soc. 1987, 109, 5227-5233.

7) Melov, S.; Ravenscroft, J.; Malik, S.; Gill, M.S.; Walker, D.W.; Clayton, P.E.; Wallace, D.C.; Malfroy, B.; Doctrow, S.R.; Lithgow, G.J. Science 2000, 289, 1567-1569.

8) Iranzo, O. Bioorg. Chem. 2011, 39, 73-87.

9) Riley, D.P.; Schall, O.F. Adv. Inorg. Chem. 2007, 59, 233-263.

10) Giblin, G.M.P.; Box, P.C.; Campbell, I.B.; Hancock, A.P.; Roomans, S.; Mills, G.I.; Molloy, C.; Tranter, G.E.; Walker, A.L.; Doctrow, S.R.; Huffman, K.; Malfroy, B. Bioorg. Med. Chem. Lett. 2001, 11, 1367-1370.

11) Doctrow, S.R.; Huffman, K.; Marcus, C.B.; Tocco, G.; Malfroy, E.; Adinolfi, C.A.; Kruk, H.; Baker, K.; Lazarowych, N.; Mascarenhas, J.; Malfroy, B. J. Med. Chem. 2002, 45, 45494558.

12) Salvemini, D.; Wang, Z.-Q.; Zweier, L.; Samouilov, A.; Macarthur, H.; Misko, T.P.; Currie, M-G-; Cuzzocrea, S.; Sikorski, J.A.; Riley, D.P. Science 1999, 286, 304-306.

13) Singh, O.; Tyagi, N.; Olmstead, M.M.; Ghosh, K. Dalton Trans. 2017, 46, 14186-14191.

14) Palopoli, C.; Gómez, G.; Foi, A.; Doctorovich, F.; Mallet-Ladeira, S.; Hureau, C.; Signorella, S. J. Inorg. Biochem. 2017, 167, 49-59.

15) Squarcina, A.; Soraru, A.; Rigodanza, F.; Carraro, M.; Brancatelli, G.; Carofiglio, T.; Geremia, S.; Larosa, V.; Morosinotto, T.; Bonchio, M. ACS Catal. 2017, 7, 1971-1976.

16) Ledesma, G. N.; Eury, H.; Anxolabehere-Mallart, E.; Hureau, C.; Signorella, S. J. Inorg. Biochem. 2015, 146, 69-76.

17) Noritake, Y.; Umezawa, N.; Kato, N.; Higuchi, T. Inorg. Chem. 2013, 52, 3653-3662.

18) Kovacs, J. Acc. Chem. Res. 2015, 48, 2744-2753.

19) Brazzolotto, D.; Reinhard, F.G.C.; Smith-Jones, J.; Retegan, M.; Amidani, L.; Faponle, A.S.; Ray, K.; Philouze, C.; de Visser, S.P.; Gennari, M.; Duboc, C. Angew. Chem. Int. Ed. 2017, $56,8211-8215$. 
20) Yosca, T.H.; Ledray, A.P.; Ngo, J.; Green, M.T. J. Biol. Inorg. Chem. 2017, 22, 209-220.

21) Gennari, M.; Brazzolotto, D.; Pecaut, J.; Cherrier, M.V.; Pollock, C.J.; DeBeer, S.; Retegan, M.; Pantazis, D.A.; Neese, F.; Rouzieres, M.; Clerac, R.; Duboc, C. J. Am. Chem. Soc. 2015, 137, 8644-8653.

22) McQuilken, A.C.; Goldberg, D.P. DaltonTrans. 2012, 41, 10883-10899.

23) Grau, M.; Rigodanza, F.; White, A.J.P.; Sorarù, A.; Carraro, M.; Bonchio, M.; Britovsek, G.J.P. Chem. Commun. 2014, 50, 4607-4609.

24) Widger, L.R.; Jiang, Y.B.; McQuilken, A.C.; Yang, T.S.; Siegler, M.A.; Matsumura, H.; Moenne-Loccoz, P.; Kumar, D.; de Visser, S.P.; Goldberg, D.P. Dalton Trans. 2014, 43, $7522-7532$.

25)Herdt, D.R.; Grapperhaus, C.A. Dalton Trans. 2012, 41, 364-366.

26) Dürr, K.; Yalalov, D.A.; Heinemann, F.W.; Tsogoeva, S.B.; Ivanovic-Burmazovic, I. Z. Naturforsch 2010, 65b, 258-262.

27) Abashkin, Y.G.; Burt, S.K. J. Phys. Chem. B 2004, 108, 2708-2711.

28) Abashkin, Y.G.; Burt, S.K. Inorg. Chem. 2005, 44, 1425-1432.

29) Abashkin, Y.G.; Collins, J.R.; Burt, S.K. Inorg. Chem. 2001, 40, 4040-4048.

30) Liu, S.-Y.; Soper, J.D.; Yang, J.Y.; Rybak-Akimova, E.V.; Nocera, D.G. Inorg. Chem. 2006, $45,7572-7574$.

31) Costas, M.; Harvey, J.N. Nat. Chem. 2013, 5, 7-9.

32)Cramer, C.J.; Truhlar, D.G. Phys. Chem. Chem. Phys. 2009, 11, 10757-10816.

33) Swart, M. Chem. Phys. Lett. 2013, 580, 166-171.

34) Gruden, M.; Stepanović, S.; Swart, M. J. Serb. Chem. Soc. 2015, 80, 1399-1410.

35) Daul, C.; Zlatar, M.; Gruden-Pavlović, M.; Swart, M. In Spin States in Biochemistry and Inorganic Chemistry: Influence on Structure and Reactivity; Swart, M., Costas, M., Eds; 
John Wiley \& Sons, Ltd, Oxford, UK, 2015; pp 7-34.

36) Fonseca Guerra, C.; Snijders, J.G.; te Velde, G.; Baerends, E.J. Theor. Chem. Acc. 1998, 99, 391-403.

37) te Velde, G.; Bickelhaupt, F.M.; Baerends, E.J.; Fonseca Guerra, C.; van Gisbergen, S.J.A.; Snijders, J.G.; Ziegler, T. J. Comput. Chem. 2001, 22, 931-967.

38) ADF2014.05, SCM, Theoretical Chemistry, Vrije Universiteit, Amsterdam, The Netherlands, http://www.scm.com

39) Swart, M.; Bickelhaupt, F.M. J. Comput. Chem. 2008, 29, 724-734.

40) Becke, A.D. Phys. Rev. A 1988, 38, 3098-3100.

41) Perdew, J.P. Phys. Rev. B 1986, 33, 8822-8824

42) Grimme, S.; Ehrlich, A.J.; Goerigk, L. J. Comput. Chem. 2011, 32, 1456-1465.

43) Klamt, A.; Schüürmann, G. J. Chem. Soc.: Perkin Trans. 1993, 2, 799-805.

44) Klamt, A. J. Phys. Chem. 1995, 99, 2224-2235.

45) Klamt, A.; Jones, V. J. Chem. Phys. 1996, 105, 9972-9981.

46) van Lenthe, E.; Baerends, E.J.; Snijders, J.G. J. Chem. Phys. 1994, 101, 9783-9792.

47) van Lenthe, E.; van Leeuwen, R.; Baerends, E.J.; Snijders, J.G. Int. J. Quantum Chem. 1996, $57,281-293$.

48) Swart, M.; Gruden, M. Acc. Chem. Res. 2016, 49, 2690-2697.

49) Swart, M.; Solà, M.; Bickelhaupt, F.M. J. Comp. Meth. Sci. Engin. 2009, 9, 69-77.

50) Swart, M. J. Chem. Theory Comput. 2008, 4, 2057-2066.

51) Swart, M.; Solà, M.; Bickelhaupt, F.M. J. Chem. Phys. 2009, 131, 094103.

52) Grimme, S. J. Comput. Chem. 2006, 27, 1787-1799.

53) Grimme, S.; Ehrlich, A.J.; Krieg, H. J. Chem. Phys. 2010, 132, 154104.

54) Padamati, S.K; Angelone, D.; Draksharapu, A.; Primi, G.; Martin, D.J.; Tromp, M.; Swart, M.; Browne, W.R. J. Am. Chem. Soc. 2017, 139, 8718-8724.

55) Grau, M.; England, J.; Torres Martin de Rosales, R.; Rzepa, S.; White, A.J.P.; Britovsek, 
G.J.P. Inorg. Chem. 2013, 52, 11867-11874.

56) Swart, M.; van Duijnen, P. T.; Snijders, J.G. J. J. Comput. Chem. 2001, 22, 79-88.

57)Carra, B.J.; Till, S.N.; VanGundy, R.A.; Pike, R.D.; Bebout, D.C. Polyhedron 2016, 114, 278-285.

58) Sproules, S.; Wieghardt, K. Coord. Chem. Rev. 2011, 255, 837-860

59) Wang, Y.; Shi, S.; Zhu, D.; Yin, G. Dalton Trans. 2012, 41, 2612-2619.

60) Kurahashi, T.; Kikuchi, A.; Shiro, Y.; Hada, M.; Fujii, H. Inorg. Chem. 2010, 49, 66646672.

61) Xu, A.; Xiong, H.; Yin, G. Chem. Eur. J. 2009, 15, 11478-11481.

62) Yin, G. Danby, A.M.; Kitko, D.; Carter, J.D.; Scheper, W.M.; Busch, D.H. J. Am. Chem. Soc. 2008, $130,16245-16253$

63) Yin, G.; Danby, A.M.; Kitko, D.; Carter, J.D.; Scheper, W.M.; Busch, D.H. J. Am. Chem. Soc. 2007, 129, 1512-1513.

64) Drzewiecka-Matuszek, A.; Rutkowska-Zbik, D.; Witko, M. Can. J. Chem. 2013, 91, 642647.

65) Mallick, D.; Shaik, S. ACS Catal. 2016, 6, 2877-2888.

66) Goldstein, S.; Meyerstein, D.; Czapski, G. Free Radic. Biol. Med. 1993, 15, 435-445.

67) Khavrutskii, I.V.; Rahim, R.R.; Musaev, D.G; Morokuma, K. J. Phys. Chem. B 2004, 108, $3845-3854$

68) Lansky, D.E.; Narducci Sarjeant, A.A.; Goldberg, D.P. Angew. Chem. Int. Ed. 2006, 45, 8214-8217

69) Annaraj, J.; Cho, J.; Lee, Y.-M.; Kim, S.Y.; Latifi, R.; de Visser, S.P.; Nam, W. Angew. Chem. Int. Ed. 2009, 48, 4150-4153.

70) Yin, G.; McCormick, J.M.; Buchalova, M.; Danby, A.M.; Rodgers, K.; Day, V.W.; Smith, K.; Perkins, C.M.; Kitko, D.; Carter, J.D.; Scheper, W.M.; Busch, D.H. Inorg. Chem. 2006, $45,8052-8061$. 
71) Garcia-Bosch, I.; Company, A.; Cady, C.W.; Styring, S.; Browne, W.R.; Ribas, X.; Costas, M. Angew. Chem. Int. Ed. 2011, 50, 5648-5653.

72) Lee, W.-T.; Xu, S.; Dickie, D.A.; Smith, J.M. Eur. J. Inorg. Chem. 2013, 3867-3873.

73) Michel, C.; Baerends, E.J. Inorg. Chem. 2009,48, 3628-3638.

74) Meunier, B.; de Visser, S.P.; Shaik, S. Chem. Rev. 2004, 104, 3947-3980.

75) Gopakumar, G.; Belanzoni, P.; Baerends, E.J. Inorg. Chem. 2012, 51, 63-75.

76) Chen, J.; Cho, K.-B.; Lee, Y.-M.;Kwon, Y.H.; Nam, W. Chem. Commun. 2015, 51, 1309413097.

77) Cho, K.-B.; Shaik, S.; Nam, W. J. Phys. Chem. Lett. 2012, 3, 2851-2856.

78) Leto, D.F.; Massie, A.A.; Rice, D.B.; Jackson, T.A. J. Am. Chem. Soc. 2016, 138, 1541315424.

79) Hull, J.F.; Balcells, D.; Sauer, E.L.O.; Raynaud, C.; Brudvig, G.W.; Crabtree, R.H.; Eisenstein, O. J. Am. Chem. Soc. 2010, 132, 7605-7616.

\section{Graphical Abstract}

